\title{
The role of the alternative pathway of complement activation in glomerular diseases
}

\author{
Emilia Łukawska ${ }^{1} \cdot$ Magdalena Polcyn-Adamczak $^{1} \cdot$ Zofia I. Niemir $^{1}$
}

Received: 21 October 2017 / Accepted: 12 February 2018 / Published online: 15 February 2018

(c) The Author(s) 2018. This article is an open access publication

\begin{abstract}
The complement system (CS) has recently been recognized as a bridge between innate and adaptive immunity that constitutes a very complex mechanism controlling the clearance of pathogens, cellular debris, and immune complexes. Out of three known pathways of complement activation, the alternative pathway (AP) plays a critical role in host defense by amplifying the complement response, independently of initiation pathway and continuously maintaining low-level activity in a process called 'thick-over.' A key molecule of the CS is C3, in which the AP is constantly activated. To prevent host cell destruction, a group of the AP regulators tightly controls this pathway of the CS activation. Acquired and genetic abnormalities of the CS may alter the delicate balance between enhancing and inhibiting the AP cascade. These can lead to the uncontrolled CS activation, inflammatory response, and subsequent tissue damage. Since complement components are locally produced and activated in the kidney, the abnormalities targeting the AP may cause glomerular injury. C3 glomerulopathy is a new entity, in which the AP dysregulation has been well established. However, recent studies indicate that the AP may also contribute to a wide range of kidney pathologies, including immune-complex-mediated glomerulonephritis (GN), pauci-immune GN, and primary membranous nephropathy (PMN). This article provides insight into current knowledge on the role of the AP in the pathogenesis of glomerular diseases, focusing mainly on various types of primary and secondary GN and PMN.
\end{abstract}

Keywords Alternative pathway of complement activation $\cdot$ Glomerular diseases $\cdot \mathrm{C} 3 \cdot$ Complement factor $\mathrm{H}$

\section{The alternative pathway of complement activation and the glomerular diseases}

The complement system (CS), discovered in 1896 by Bordet, is the key element combining innate and adaptive immune system. A wide range of its biological activity is due to the cooperation of more than 30 plasma proteins $[1,2]$. Due to its ability to differentiate between healthy and foreign or damaged cells, it plays an important role in protecting against pathogens by opsonization of bacterial cells and viruses, chemotaxis, initiation of the inflammatory response at the site of infection, elimination of modified or damaged cells, and removal of immune complexes. In humans, the complement can be activated via the three

Zofia I. Niemir

zniemir@ump.edu.pl

1 Laboratory of Molecular Nephrology, Department of Nephrology, Transplantology and Internal

Diseases, Poznan University of Medical Sciences, Al.

Przybyszewskiego 49, 60-355 Poznan, Poland pathways: classical (CP), alternative (AP), and lectin (LP) [1-6]. C3 is the most abundant complement protein, present in all three pathways [2,3], but its role is particularly crucial for the AP generation. Since constant activation in plasma via the AP may target both foreign and hosts cells, the AP-regulating proteins tightly control this pathway [1]. Genetic and acquired abnormalities in both AP components and AP-regulating proteins may lead to an uncontrolled AP activation and subsequent renal injury. Increased knowledge of complement and its role in the pathogenesis of kidney diseases has recently led to the reclassification of glomerulonephritis (GN) based on pathophysiology rather than pathomorphology. A new entity, called C3 glomerulopathy (C3G), characterized by the AP dysregulation has been distinguished [7-10]. The remaining renal pathologies have been categorized as immune-complex GN, pauci-immune $\mathrm{GN}$, anti-glomerular basement membrane (GBM) GN and monoclonal immunoglobulin (Ig) GN. The primary membranous nephropathy (PMN), podocytopathies, and thrombotic microangiopathy (TMA) have not been included in the GN group [7]. In this review, we focus on the pathophysiology of 
the AP, as a crucial part of the complement system and analyze its role in the pathogenesis of kidney diseases, mainly in various forms of primary and secondary GN, and PMN.

\section{The C3 protein: a key component of the alternative pathway of complement system}

\section{C3 structure}

Human $C 3$ gene is localized on the chromosome 19 (19p13,2-13,3) and consists of 41 exons (52-213 bp). The C3 protein is synthetized mainly in the liver, but $C 3$ gene is also expressed in monocytes, neutrophils, fibroblasts, antigen-presenting cells, epithelium of the renal tubules and capillary endothelium. A precursor protein, the $\mathrm{C} 3$ preproprotein (preproC3) is built of one polypeptide chain, which comprises of 1663 amino acids. It undergoes several posttranslational modifications, such as cleavage of the $\mathrm{N}$-terminal 22 amino acids long signal peptide, removal of the four arginine residues by furin-like enzyme, glycosylation and the internal thioester bond formation $[4,6,11$, 12]. The mature $\mathrm{C} 3$ protein $(185 \mathrm{kDa})$, which is released from endoplasmic reticulum to the plasma is divided into two chains: $\beta$ (residues 1-645, $75 \mathrm{kDa}$ ) and $\alpha$ (residues 650 $1641,110 \mathrm{kDa}$ ). They are combined by a disulfide bridge at the position 917 in $\alpha$ chain and the position 63 in the $\beta$ chain (Fig. 1) $[3,6,11]$. Finally, the $\mathrm{C} 3$ protein comprises of 8 macroglobulin domains (MG1-8) that have specific binding sites for complement receptors (C3aR, CR1, CR2, $\mathrm{CR} 3$ ) and AP-regulating proteins, as well as the thioester (TED) and CUB domains. TED domain, localized in the C3d region, consists of an internal thioester bond between cysteine (Cys988) and glutamine (Gln991). TED is responsible for attachment to the cell surface, which is crucial for the AP activation. The thioester group of circulating $\mathrm{C} 3$ is continuously hydrolyzed at a rate of about $1 \%$ of total C3 per hour. This process, called C3 'thick-over,' results in a formation of conformationally altered $\mathrm{C} 3\left(\mathrm{H}_{2} \mathrm{O}\right)$, capable of binding either to complement factor $\mathrm{H}(\mathrm{CFH})$ or complement factor B (CFB) (but not to the cell surfaces). It is an

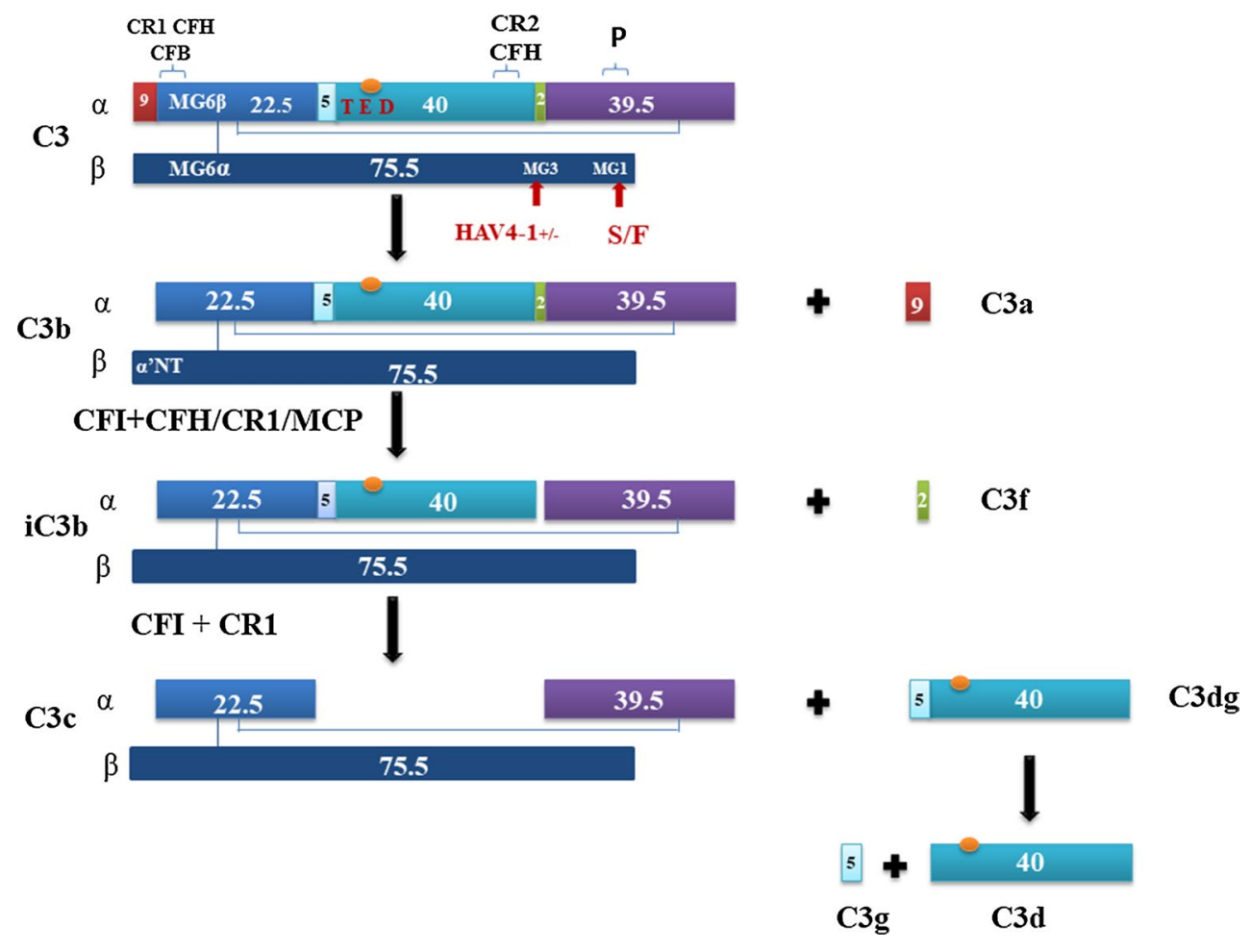

Fig. 1 The structure of the $\mathrm{C} 3$ protein and $\mathrm{C} 3$ proteolytic cascade. The mature C 3 comprises of the two chains (alpha, $\alpha$, and beta, $\beta$ ) combined covalently by a single disulfide bond between macroglobulin six alpha (MG6 $\alpha$ ) in the $\beta$-chain and macroglobulin six beta (MG6 $\beta$ ) in the $\alpha$-chain. The $\beta$-chain is coded by the first 16 exons of the $\mathrm{C} 3$ gene (645 residues), and the $\alpha$-chain is coded by the following 25 exons (992 residues). The $\beta$ chain comprises of the macroglobulin domains (MG1-6 $\alpha$ ) and linking region (LNK), while the $\alpha$ chain is built of the MG6 $\beta-8$, CUB, C345, anchor, thioester (TED), and anaphylatoxin (ANA or $\mathrm{C} 3 \mathrm{a}$ ) domains. The $\mathrm{C} 3$ cleavage to $\mathrm{C} 3 \mathrm{a}$ and $\mathrm{C} 3 \mathrm{~b}$, enables $\mathrm{C} 3 \mathrm{~b}$, containing TED, to bind to the activating surfaces. The numbers (in kilodaltons) show the molecular masses of the corresponding proteins. The red arrows indicate the site of the common $\mathrm{C} 3$ polymorphisms (F/S and HAV 4-1+/-), located in MG1 and MG3, respectively. The diagram was based on Maillard et al. [32], modified 
important mechanism preventing the destruction of the host cells [3, 13-15].

\section{C3 function}

C3 is a key component of the innate immune system, involved in a very efficient mechanism identifying and destroying pathogens. Rare, congenital C3 deficiencies are associated with the impairment of the immune response predisposing to the development of severe diseases like systemic lupus erythematosus (SLE) and recurrent pyogenic infections, caused by encapsulated bacteria, including pneumonia, sepsis, otitis media, tonsillitis and meningitis $[4,11$, 12]. Presently, it is believed that aside from the traditional three pathway model of activation of the CS, various other factors may contribute to the $\mathrm{C} 3$ amplification. The current view on the complement system activation shifts from a traditional stiff division on the three distinct pathways to a very complex network of cooperating proteins, activators and regulators, in which the key player is $\mathrm{C} 3$ protein. This seems to be supported by the reports on the growing role of properdin (FP) as a recognition pattern molecule, which can activate AP by binding to C3b. Also, $\mathrm{C} 3$ and $\mathrm{C} 5$ can be directly activated by 'extrinsic' proteases that are not traditionally associated with the complement system, for example, thrombin and plasmin [16, 17]. The $\mathrm{CP}$ is triggered by $\mathrm{IgG}$ and or IgM-containing immune complexes, viruses and acute-phase proteins, binding to C1q. A C1qrs complex is formed, which then cleaves $\mathrm{C} 4$ and $\mathrm{C} 2$. When the LP is activated, polysaccharide molecules (mannose, fructose or $\mathrm{N}$-acetyl glucosamine) on bacterial surface bind to mannan-binding lectin (MBL), leading to the cleavage of $\mathrm{C} 4$ and $\mathrm{C} 2$. Both the CP and LP result in a formation of the $\mathrm{C} 3$ convertase $(\mathrm{C} 4 \mathrm{bC} 2 \mathrm{a})$. The AP is activated spontaneously by the constant thioester hydrolysis in the $\mathrm{C} 3$ protein. When the stable form, $\mathrm{C} 3\left(\mathrm{H}_{2} \mathrm{O}\right)$, binds to $\mathrm{CFB}$ in the presence of a serine protease complement factor $\mathrm{D}$ (CFD), CFB itself is cleaved to $\mathrm{Bb}$ and $\mathrm{Ba}$, resulting in $\mathrm{C} 3\left(\mathrm{H}_{2} \mathrm{O}\right) \mathrm{Bb}$ ('initiation' $\mathrm{C} 3$ convertase) creation. As a serine protease, $\mathrm{Bb}$ cleaves additional $\mathrm{C} 3$ molecules, generating $\mathrm{C} 3 \mathrm{a}$ (anaphylatoxin) and $\mathrm{C} 3 \mathrm{~b}$. As a vasoactive peptide, $\mathrm{C} 3 \mathrm{a}$ mediates inflammatory responses, stimulates mastocytes' degranulation, and plays an important role in chemotaxis. It acts as a precursor of protein acylation by interacting with carboxypeptidase B. C3b may covalently bind via thioester bridge to the activating surfaces or associate with $\mathrm{CFB}$ to generate $\mathrm{C} 3 \mathrm{bBb}$ ('amplification' C3-convertase). This proteolytic cascade is enhanced by FP, which stabilizes $\mathrm{C} 3$ convertase and also promotes further convertase assembly, and $\mathrm{C} 3 \mathrm{~b}$ deposition. Surface-bound $\mathrm{C} 3$ convertase associates with circulating $\mathrm{C} 3$ by forming dimers between $\mathrm{C} 3$ and $\mathrm{C} 3 \mathrm{bBb}$. The location of $\mathrm{Bb}$ in a flexible $\mathrm{C} 345 \mathrm{C}$ domain of $\mathrm{C} 3 \mathrm{~b}$ facilitates the cleavage of $\mathrm{C} 3$ into $\mathrm{C} 3 \mathrm{a}$ and $\mathrm{C} 3 \mathrm{~b}$. At this point, either both
$\mathrm{C} 3 \mathrm{a}$ and $\mathrm{C} 3 \mathrm{~b}$ are released to the circulation or, only $\mathrm{C} 3 \mathrm{a}$ is released, and $\mathrm{C} 3 \mathrm{~b}$ remains attached to the $\mathrm{C} 3 \mathrm{bBb}$ complex, thus gaining the $\mathrm{C} 5$ convertase activity. Additionally, the AP C5 convertase formation is enhanced by FP. Finally, C3b attached to the activating surfaces, generated in the $\mathrm{CP}$ or $\mathrm{LP}$, may also create $\mathrm{C} 3 \mathrm{bBb}$. In the end, the $\mathrm{C} 3$ convertases $(\mathrm{C} 4 \mathrm{bC} 2 \mathrm{a}$ or $\mathrm{C} 3 \mathrm{bBb}$ ) bind $\mathrm{C} 3$ and create the $\mathrm{C} 5$ convertases (C4bC2aC3b or $\mathrm{C} 3 \mathrm{bBbC} 3 \mathrm{~b}$ ), promoting $\mathrm{C} 5$ cleavage to $\mathrm{C} 5 \mathrm{a}$ and $\mathrm{C} 5 \mathrm{~b}$. The generation of all three pathways leads to a cascade of enzymatic reactions, resulting in a formation of the membrane attack complex C5b-9 (MAC), which can destroy cell membranes and causes lysis of non-nucleated cells (e.g., bacteria or erythrocytes). In case of nucleated cells, it induces activation of inflammatory response and tissue damage (Fig. 2) [1, 6, 15, 17-25].

A unique feature of $\mathrm{C} 3$ is an ability to attach to the acceptor molecules on the cell surfaces. It is possible due to the presence of the TED domain in the C3d region. During posttranslational modifications, the thioester bond between the thiol group of cysteine (Cys988) and a $\gamma$-amide group of glutamine (Gln991) is created. The cleavage of C3 to C3a and $\mathrm{C} 3 \mathrm{~b}$ causes a conformational change in the remaining $\mathrm{C} 3 \mathrm{~b}$ molecule, resulting in the exposure of the thioester bond. Therefore, C3b may covalently bind to aldehydes, carboxyl groups, and nitrogen nucleophiles on the cell surfaces, and to the immune complexes. The $\mathrm{C} 3 \mathrm{~d}$ region plays an important role in lymphocytes B activation by interacting with CR1 and CR2 on lymphocytes B or T and dendritic cells, and in enhancing phagocytosis. It is also a binding site for $\mathrm{CFH}$ and CR2 [3, 4, 12, 15, 20].

Another vital function of the $\mathrm{C} 3$ protein is capturing and clearance of immune complexes. The covalent bond between $\mathrm{C} 3 \mathrm{~b}$ and $\mathrm{N}$-terminal $\mathrm{IgG}$ domain suppresses reactions with $\mathrm{Fc}$ receptor. It also decreases the formation of the new immune complexes and dissolves existing ones. $\mathrm{C} 3 \mathrm{~b}$ proteins combined with immune complexes are bound to CR1 on erythrocytes and then transported to the liver and spleen, where they undergo phagocytosis by macrophages or monocytes $[4,22,26]$. The imbalance between the production and removal of immune complexes may lead to the inflammatory response and tissue damage. The concentration of $\mathrm{C} 3$ in plasma varies from 0.8 to $1.9 \mathrm{mg} / \mathrm{mL}[12,27]$. In an acute-phase reaction, in response to proinflammatory agents, including interleukin 1 (IL-1) or IL-6, tumor necrosis factor- $\alpha$, interferon- $\gamma$, and lipopolysaccharide, 2-to 3-fold increase in C3 concentration may be observed [12]. Moreover, recent studies have established that fluid phase $\mathrm{C} 3 \mathrm{~b}$ or $\mathrm{C} 3\left(\mathrm{H}_{2} \mathrm{O}\right)$ may be recruited by FP bound to the necrotic and apoptotic human cells, acting as a pattern recognition molecule $[17,18]$.

The anaphylatoxins, C3a and C5a, have a strong chemotactic influence on phagocytes such as neutrophils and mast cells, attracting them to the site of inflammation. 


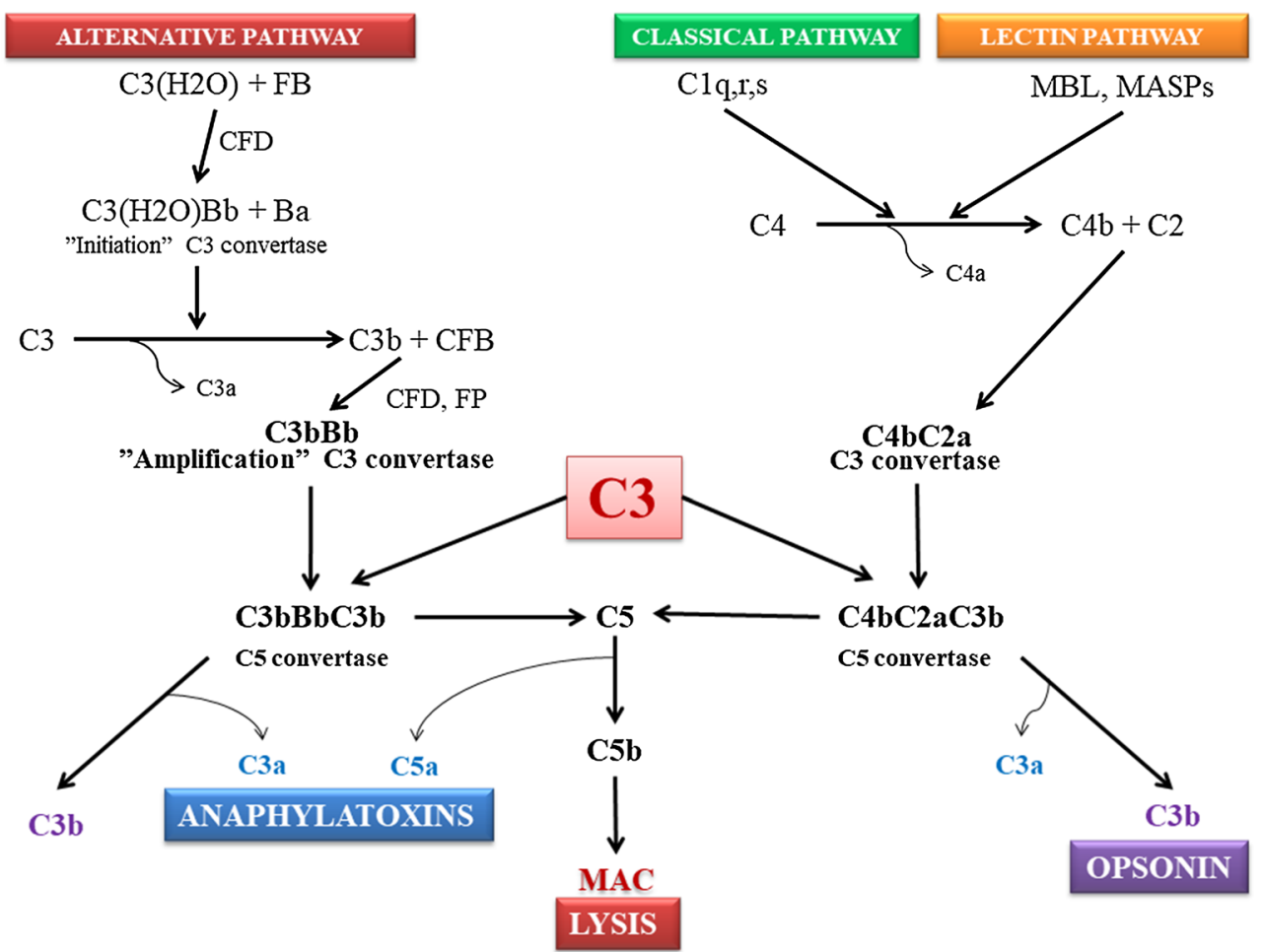

Fig. 2 The complement cascade. The diagram was based on Dunkelberger et al. [1] and Rochowiak et al. [22], modified

They also cause vessel dilatation by stimulating mastocytes and basophils to release histamine and induce oxidative bursts in neutrophils and eosinophils. C5a is also a promoter of necrotic and inflammatory lesions in the glomeruli, contributing to renal fibrosis and impairment of kidney function. However, C3a alone also acts as an anti-inflammatory agent in an acute phase of inflammation by suppressing neutrophil migration and degradation. [16, 20, 23, 26].

$\mathrm{C} 3 \mathrm{~b}$ is an opsonin, which may bind to various factors. This binding determines activation or deactivation of those factors. For instance, $\mathrm{C} 3 \mathrm{~b}$, attached to the surface, may bind $\mathrm{CFB}$ and form the $\mathrm{C} 3$ convertase, and later C5 convertase. As a result, C5 is cleaved into C5a and $\mathrm{C} 5 \mathrm{~b}$. The latter induces MAC formation with its cytolytic activity. C5a promotes migration of neutrophils to the site of inflammation [4]. At the same time, more and more $\mathrm{C} 3 \mathrm{~b}$ molecules are accumulated on the surface of pathogens. This process enhances the immunological humoral response, enables phagocytosis, and leads to the elimination of autoreactive $\mathrm{B}$ cells $[3,4,15,20]$. Conversely, when $\mathrm{C} 3 \mathrm{~b}$ binds to $\mathrm{CFH}$, it becomes unable to bind $\mathrm{CFB}$, what prevents $\mathrm{C} 3$ convertase formation and further activation of AP. This phenomenon was explained by studies on the crystal structure of $\mathrm{C} 3 \mathrm{~b}-\mathrm{CFH}$, which revealed the overlapping binding sites on $\mathrm{C} 3 \mathrm{~b}$ for both CFB and CFH [28].

\section{The alternative pathway regulating proteins}

Since the AP is constantly activated in plasma, to prevent host cells and tissue destruction, it has to be tightly regulated. There are various types of the AP controlling proteins. Some of them like complement receptor (CR1), membrane cofactor protein (MCP, CD46), decay accelerating factor (DAF, CD55) and CFH act on the cell surfaces, and the other such as $\mathrm{CFH}$ and complement factor I (CFI) act in plasma. MCP, DAF, CR1, and CFH share several similarities in structure and function. All of them consist of highly conservative domains, called short consensus repeats (SCRs), which bind in the same orientation to the same platform on $\mathrm{C} 3 \mathrm{~b}$. MCP possess cofactor activity and binds to C3b via SCRs3-4, DAF exhibits decay acceleration properties and binds to $\mathrm{C} 3 \mathrm{~b}$ via SCRs $2-4$, whereas CR1 interacts with C3b through SCRs 15-17 and has both cofactor and decay acceleration activity [22, 29, 30]. Out of them, unique is $\mathrm{CFH}$, as it inhibits AP both in the fluid phase and on the cell surfaces. CFH is a soluble glycoprotein, encoded by the single gene, located on the chromosome 1q32, in the regulators of complement activation (RCA) gene cluster (Fig. 3). Its serum concentrations may range from 110 to $615 \mu \mathrm{g} / \mathrm{mL}[1,4,31,32]$. The molecular structure of $\mathrm{CFH}$ consists of $20 \mathrm{SCRs}$, which are arranged 


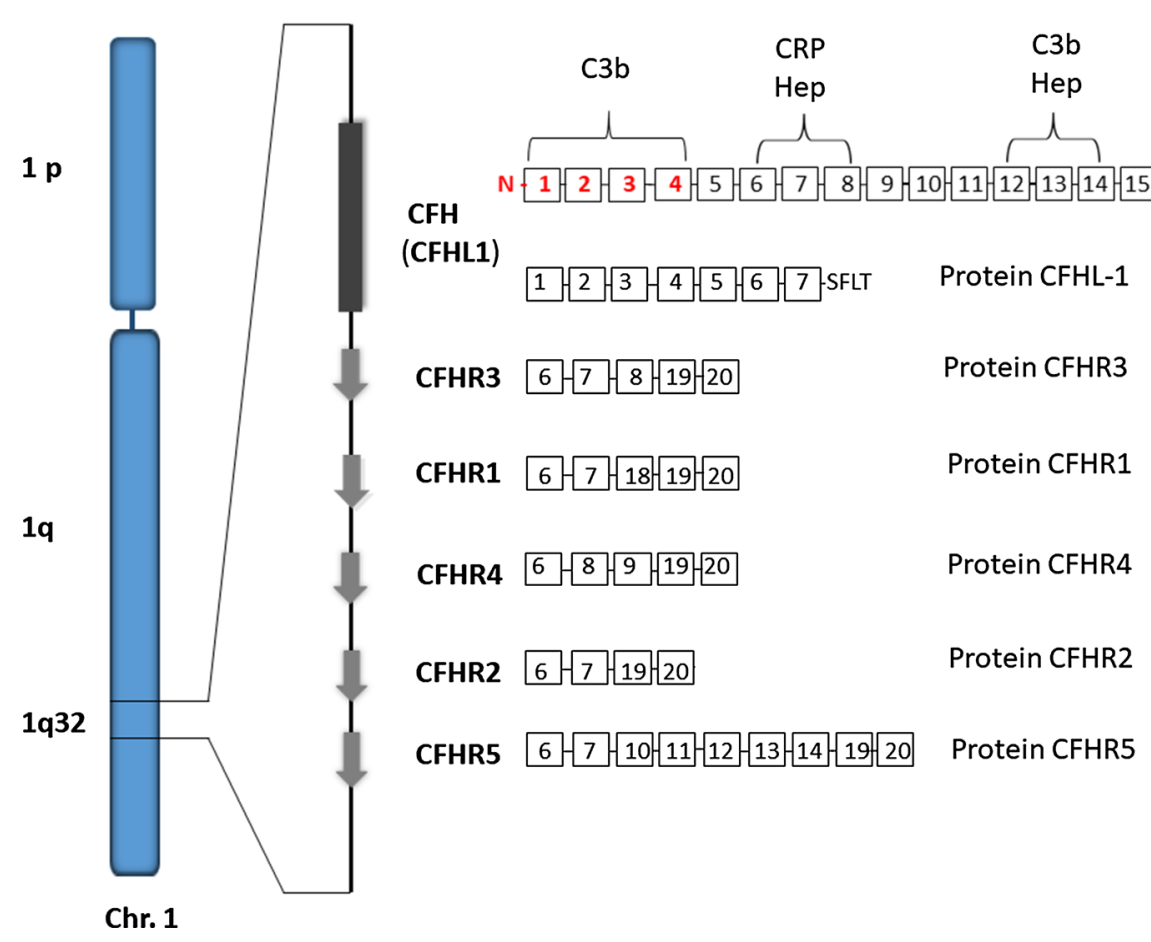

Fig. 3 The location of the RCA gene cluster on the chromosome 1q32 encoding $\mathrm{CFH}$ and the family of CFH-related proteins (CFHR1-5). $\mathrm{CFH}$ comprises of 20 SCRs. Although the CFHR1-5 proteins contain the structurally and functionally similar SCRs (19-20 binding $\mathrm{C} 3 \mathrm{~b}$ and polyanions), they do not possess the regulatory sequence (SCR 1-4). The N-terminal end (SCR1-4) binds to C3b and C3 convertase in the fluid phase (marked red). The C-terminal end (SCR1920 ) is responsible for surface-bound regulation of the AP, by binding to $\mathrm{C} 3 \mathrm{~b}$, heparin or sialic acid attached to the surface (marked

in a head to tail fashion, with $\mathrm{C} 3 \mathrm{~b}$ binding sites on both $\mathrm{N}$-terminal and $\mathrm{C}$-terminal ends. The $\mathrm{N}$-terminal end is a cofactor in CFI-dependent $\mathrm{C} 3 \mathrm{~b}$ proteolysis and mediates accelerated decay of $\mathrm{C} 3 \mathrm{Bb}$ in a fluid phase. $\mathrm{CFH}$ in the presence of CFI inhibits the AP by generating iC $3 \mathrm{~b}$, which is unable to form the $\mathrm{C} 3$ convertase; $\mathrm{iC} 3 \mathrm{~b}$ is further degraded to $\mathrm{C} 3 \mathrm{c}$ and $\mathrm{C} 3 \mathrm{dg}$ (Fig. 1). Detection of $\mathrm{iC} 3 \mathrm{~b}$ split products, such as iC $3 \mathrm{~b}, \mathrm{C} 3 \mathrm{dg}, \mathrm{C} 3 \mathrm{c}$, and $\mathrm{C} 3 \mathrm{~d}$, is a useful method of monitoring the AP activation. The more detailed insight on the cofactor and decay acceleration activity of $\mathrm{CFH}$ is provided by the crystal model of the first four SCRs of CFH in complex with C3b. Although CFI possesses weak ability to bind to $\mathrm{C} 3 \mathrm{~b}$, it is the only known protein that can cleave $\mathrm{C} 3 \mathrm{~b}$. Its function is dependent on the presence of the AP regulators. To degrade $\mathrm{C} 3 \mathrm{~b}$, CFI requires the assistance of $\mathrm{CFH}, \mathrm{MCP}$ or $\mathrm{CR} 1$, which bring CFI near CUB domain. By binding to SCRs 1-3 of $\mathrm{CFH}$ and $\mathrm{C} 345 \mathrm{C}$ of $\mathrm{C} 3 \mathrm{~b}, \mathrm{CFI}$ cleaves either two or three distant peptide bonds in the CUB domain of C3b. Also, the SCR 4 of CFH forms a bridge between TED and the core of C3b (precisely MG1), providing a platform for CFI cofactor activity and, possibly supporting the position green). Mutations or autoantibodies directed to either N-terminal or $\mathrm{C}$-terminal end of the $\mathrm{CFH}$ protein are associated with the development of $\mathrm{C} 3 \mathrm{G}$ or aHUS, respectively. Complement factor H-like protein (CFHL-1) is a short isoform of $\mathrm{CFH}$, resulting from the alternative splicing of the $C F H$ gene. CFHL- 1 consists of SCRs 1-7 and possesses a hydrophobic end, containing seven amino acids (SFLT). Hep heparin; NANA sialic acid; The diagram was based on AbreraAbeleda et al. [34], modified

of TED while connecting CUB domain undergoes further cleavage. The decay acceleration activity of $\mathrm{CFH}$ is due to dislocation of $\mathrm{Bb}$ protease, occurring as a result of binding between the first two N-terminal SCR of FH and the $\alpha$ 'NT, MG2 and MG6-7 domains of C3b [30, 33]. The C-terminal end binds to $\mathrm{C} 3 \mathrm{~b}$ TED domain and polyanions (glycosaminoglycans, GAG) on the cell surfaces [29]. This ability is crucial to distinguish between host and pathogen cells, which typically do not contain GAG on their surfaces. CFH is expressed on many surfaces not possessing any other AP-regulating proteins. In fact, it is the only AP inhibitor present on the GBM in glomeruli. Complement FH-like protein (CFHL1), a splice form of $\mathrm{CFH}$, consisting of $7 \mathrm{~N}$-terminal domains of $\mathrm{CFH}$ has also been reported [1, 20, 24-26, 32]. 


\section{The role of complement factor H-related proteins (CFHR1-5)}

Recently described, the complement FH-related proteins (CFHR1-5) are also the members of the RCA gene cluster, encoded by five genes on chromosome 1q32. Although they exhibit high sequence homology with the surfacebinding domains of $\mathrm{CFH}$, none of them possesses the regulatory SCRs 1-4 domains (Fig. 3). Due to their similarity to $\mathrm{CFH}$, it was suggested that they act mainly as AP inhibitors. For instance, it was reported that CFHR1 might inhibit the $\mathrm{C} 5$ convertase and MAC formation, but not $\mathrm{C} 3 \mathrm{bBb}$, whereas $\mathrm{CFHR} 2$ was shown to inhibit $\mathrm{C} 3$ convertase in vitro. While CFHR 3 and CFHR4 were revealed to possess a weak FI cofactor activity, CFHR5 bound C $3 \mathrm{~b}$ in vitro and exhibited both FI cofactor and decay acceleration activity. However, most of these AP-regulating activities of CFHRs are weak, and they were observed in in vitro assays, which used non-physiological CFHRs concentrations [23, 24, 31, 32, 34-36].

In spite of the structural homology to $\mathrm{CFH}$ and reports of CFHRs AP regulatory activity, studies that are more recent have suggested that CFHRs are more likely to be complement activators rather than inhibitors. Several different hypotheses have been proposed to explain this phenomenon. First, CFHRs may compete with CFH for the same binding site on $\mathrm{C} 3 \mathrm{~b}$, but because of lack of the regulatory domains, they do not exhibit both cofactor and decay acceleration activity. This process was called complement deregulation, and so far, CFHR1, CFHR2, and CFHR5 have been described to be a competitive antagonist of CFH [37-40]. Secondly, CFHR5 may deregulate complement indirectly by competing with $\mathrm{CFH}$ in binding to other than $\mathrm{C} 3 \mathrm{~b}$ physiological ligands, including pentraxin PTX3, CRP and extracellular matrix [36]. Also, CFHR4 and CFHR5 have been reported to directly promote $\mathrm{C} 3$ convertase formation by binding to $\mathrm{C} 3 \mathrm{~b}$, with stronger ability to assemble $\mathrm{C} 3 \mathrm{bBb}$ on CFHR4, and with $\mathrm{C} 3 \mathrm{bBb}$ CFHR4 complex being more resistant to $\mathrm{CFH}$ cleavage in comparison with $\mathrm{C} 3 \mathrm{bBb}[36,41,42]$.

The unique property of CFHRs is the ability to form dimers. CFHR-1, CFHR-2, and CFHR-5 homodimerize, with CFHR1-CFHR1 homodimers being the most frequent. In case of CFHR-1 and CFHR-2, they also form CFHR1CFHR2 heterodimers. Since CFHR1, CFHR2, and CFHR5 monomers were not detected in human sera, they are suspected of creating dimers directly after being released to plasma [42]. The CFHR5 ability to form heterodimers is controversial. In the recent study performed by van Beek et al., CFHR1-CFHR5 and CFHR2-CFHR5 heterodimers were absent in human plasma [42]. It has to be underlined that the results of this report are in opposition to the former (based on in vitro assays) suggesting that dimerization confers avidity for tissue-bond complement fragments and thus may enhance complement deregulation [38]. According to the latter study, serum levels of CFHR-1-CFHR1, CFHR1-CFHR2, CFHR-2-CFHR2, and CFHR-5-CFHR5 dimers were low compared to $\mathrm{CFH}$, which circulates at a 10 - to
Fig. 4 The common $\mathrm{C} 3$ polymorphisms. a. A singlenucleotide change (cytosine for guanine) at the position 364 in the exon 3 of the $\beta$ chain in the $C 3$ gene causes a substitution of a positively charged arginine residue in $\mathrm{C} 3 \mathrm{~S}$ by a neutral glycine residue in $\mathrm{C} 3 \mathrm{~F}$. b A singlenucleotide change (cytosine for thymine) at the position 314 in the exon 9 of the $\beta$ chain in the $C 3$ gene causes a substitution of proline in HAV4-1- by leucine in HAV4-1+. The diagram was based on Botto et al. [45], modified
A
C3 S/F (rs2230199) p.R102G

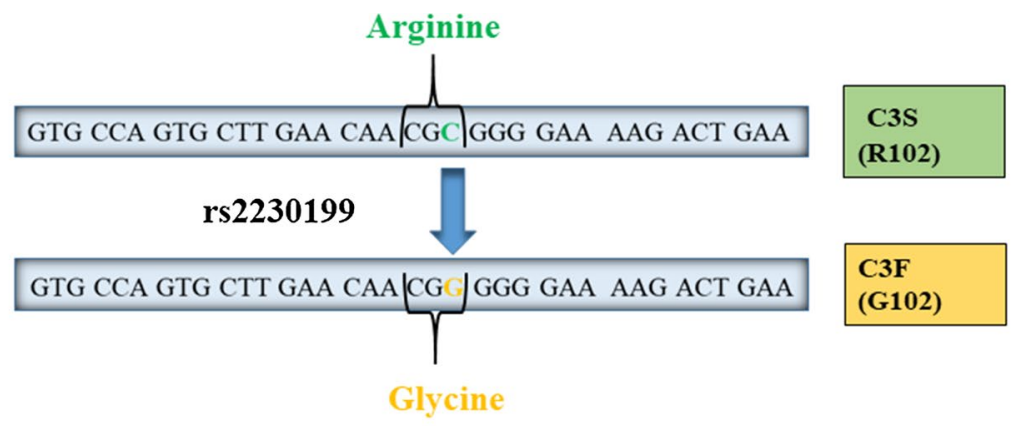

B

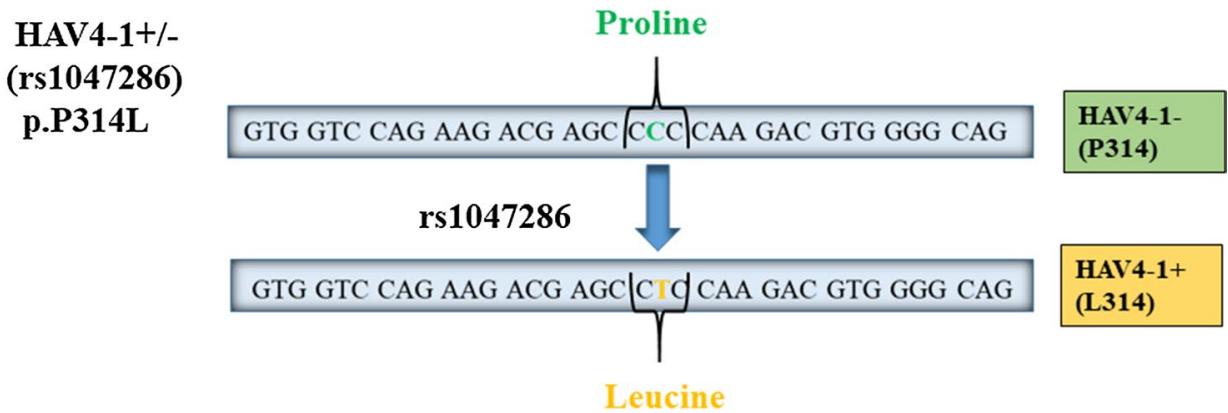


200-fold molar excess. Therefore, these dimers are not supposed to compete efficiently with $\mathrm{CFH}$ [42].

\section{The genetic background of the AP abnormalities in glomerular diseases}

In 1967, two independent groups of scientists identified the most common to date single-nucleotide polymorphism (SNP) in the $C 3$ gene (Figs. 1, 4), termed C3S/F or p.R102G (rs2230199) [43, 44]. While performing electrophoresis, they found a double strand representing $\mathrm{C} 3$ in the $\beta$-globulin region. The difference in mobility between the $\mathrm{C} 3$ proteins from different blood samples in an agarose gel led to the discovery of the three polymorphic variants: homozygote C3S (Slow), homozygote C3F (Fast), and heterozygote C3S/F. As electrophoresis was a time-consuming method and required a fresh blood sample, Botto et al. used polymerase chain reaction (PCR) with subsequent restriction fragment length polymorphism (RFLP) to localize the genome position of $\mathrm{C} 3 \mathrm{~S} / \mathrm{F}$. They found that in $\alpha$ chain of the $\mathrm{C} 3$ protein at position 364 in the exon three cytosine $(C)$ is changed into guanine $(\mathrm{G})$, thus resulting in a polymorphic restriction site for the enzyme HhaI. At the protein level, positively charged arginine (Arg80) is replaced with neutral glycine [45]. Later, the three-dimensional analysis of C3, performed by Janssen et al., located rs2230199 in the MG1 domain near the TED domain of the $\mathrm{C} 3$ protein. Three positively charged amino acids in the MG1 domain (Arg80, Arg72, and Lys82) form the thioester bond with four negative amino acids in the TED domain (Asp1007, Glu1008, Glu1010, Glu1013). The C3F variant, containing neutral glycine (instead of positively charged arginine), has a weaker ability to bind to $\mathrm{CFH}$, which may impair the downregulation of the AP convertase, thus altering the $\mathrm{C} 3$ function [14, 46, 47]. The frequency of $\mathrm{F}$ allele varies among different populations, and it is the highest in Caucasian (18\%) and the lowest in Asian (1\%) [6, 48]. Koch et al., using purified C3S and C3F as immunogens, and monoclonal mouse antibody (HAV4-1), described another common $\mathrm{C} 3$ polymorphism called HAV41+/- (rs 1047286, p.P314L). The authors reported C3 variants that bind to murine monoclonal antibodies (HAV4-1 positive, HAV4-1+) and variants that do not (HAV4-1 negative, HAV4-1-) [49]. Rs 1047286 is localized in the exon 9 of beta chain, where a single change of cytosine for thymine causes a substitution of proline (HAV 4-1-, P314) for leucine (HAV 4-1+, L314) at the protein level (Fig. 4). Rs 1047286 is linked to rs2230199. It has been estimated that $98 \%$ of C3S allele carriers is HAV4-1- and only $2 \%$ is HAV4-1+; on the contrary, $90 \%$ carriers of the C3F allele is HAV4- $1+$ and $10 \%$ is HAV4-1- [45]. As rs1047286 is located in the MG3 domain of $\mathrm{C} 3$ (binding site of CFB), polymorphic variant
HAV4-1+ has stronger ability to bind to CFB (Fig. 1) [46, 50].

Differences in the structure and function of polymorphic C3 allotypes may contribute to the occurrence, as well as the severity of complement-related diseases. Carries of $\mathrm{C} 3 \mathrm{~F}$ allele are at risk for the development of age-related macular degeneration (AMD) [46], partial lipodystrophy (PD) [51], and various types of GN: membranoproliferative glomerulonephritis type II (MPGN II, presently known as dense deposit disease, DDD) [51, 52], IgA nephropathy (IgAN) $[53,54]$ and systemic vasculitis (SV) $[55,56]$. Surprisingly, $\mathrm{C} 3 \mathrm{~F}$ allele has been shown to have a protective effect on transplant kidney, and its presence in donor's kidney may prolong the graft survival [57]. The common C3S/F comprises approximately $98 \%$ of all C3 phenotypes. To date, other $\mathrm{C} 3$ polymorphic variants have also been described (Table 1) [58-62].

In 2001, a homozygous mutation (Tyr1081Ter) in the $C 3$ gene with the complete serum $\mathrm{C} 3$ deficiency was reported in two Japanese sisters, who developed SLE-like symptoms [58]. In 2008, Miyagawa et al. [59] described an association between the SNP located in the exon 15 of $C 3$ gene $(C>T$; rs7951) and serum concentration of $\mathrm{C} 3$, as well as susceptibility to SLE in the Japanese population. The link between this polymorphism and serum C3 levels was confirmed in Caucasians 1 year later, but other SNPs in the $C 3$ gene have been revealed to be related with susceptibility to SLE (intron 27; A > C; rs 3745568) or higher C3 serum levels (intron 37; $\mathrm{G}>\mathrm{A} ; \mathrm{rs} 344555)$ in this ethnic group [60].

Recently, the results of studies on SNPs occurring in the other AP proteins including CFB, MCP, CFH, and CFHRs and their associations with the glomerular disease have been published (Table 1). So far, the most relevant linkage with GN has been found with SNPs in $C F H$ gene. The two common $C F H$ SNPs, resulting in amino acid substitution and subsequent change of the protein function, are $\mathrm{Y} 402 \mathrm{H}$ ( $\mathrm{rs} 1061170)$ and V62I (rs800292). Y402H polymorphism (rs1061170) is defined by T-to-C transition at amino acid position 402 (CRP and heparin binding site), resulting in the substitution of Tyr402 by His402 [12, 34]. In case of V62I (rs800292), guanine $(\mathrm{G})$ is changed to adenine (A), causing single amino acid change (valine to isoleucine transition) [34, 63]. Both SNPs are reported to be associated with various diseases including C3G, SLE and AMD [50, 63-68]. The genome-wide association studies (GWAS) suggest that cumulative, synergistic effect of some SNPs, mainly in $C 3$ and $C F H$ genes, rather than a single mutation, contribute to the glomerular disease [50,65]. Although the CFH binding sites and the common C3 SNPs are situated in two different chains ( $\alpha$ and $\beta$, respectively) of the $\mathrm{C} 3$ molecule (Fig. 1), the 3D model of $\mathrm{C} 3$ places the MG1 (C3S/F; rs2230199) and $\mathrm{C} 3 \mathrm{~d}$ region (CFH binding site) in a close proximity $[14,47]$. This implicates the possibility that the presence of many different risks variants of $\mathrm{C} 3$ and $\mathrm{CFH}$ 
Table 1 The most common mutations predisposing to AP-related glomerulonephritides

\begin{tabular}{|c|c|c|c|}
\hline Mutations & $\mathrm{C} 3 \mathrm{G}$ & $\begin{array}{l}\text { Immune-complex- } \\
\text { mediated GN }\end{array}$ & $\begin{array}{l}\text { Pauci- } \\
\text { immune } \\
\text { GN }\end{array}$ \\
\hline
\end{tabular}

\begin{tabular}{|c|c|c|c|}
\hline \multicolumn{4}{|l|}{ C3 gene } \\
\hline $\mathrm{C} 3 \mathrm{~S} / \mathrm{F}$ (rs2230199) $[50-52,55,56]$ & + & + & + \\
\hline HAV4-1+/- (rs1047286) [50] & $+(\mathrm{DDD})$ & - & - \\
\hline c.C1775T/p.R592Q (rs121909583) [101] & + & - & - \\
\hline V619 M (rs146613648) [64] & + & - & - \\
\hline R1303H [64] & + & - & - \\
\hline R13200Q [64] & + & - & - \\
\hline C1518R [64] & + & - & - \\
\hline D1625H [64] & + & - & - \\
\hline$\Delta$ DG3923 [64] & $+(\mathrm{DDD})$ & + & - \\
\hline c.131_146del; p.Leu44Argfs*19 [73] & - & $+(\mathrm{SLE})$ & - \\
\hline IVS38AS, A-G [57] & - & $+(\mathrm{SLE})$ & - \\
\hline Tyr1081Ter [58] & - & $+(\mathrm{SLE})$ & - \\
\hline rs $3745568[60]$ & - & $+(\mathrm{SLE})$ & - \\
\hline rs344555 [60] & - & $+(\mathrm{SLE})$ & - \\
\hline rs7951 [59] & - & $+(\mathrm{SLE})$ & - \\
\hline V86I [64] & - & + & - \\
\hline $\mathrm{R} 505 \mathrm{C}[64]$ & - & + & - \\
\hline G637R [64] & - & + & - \\
\hline K1051 M [64] & - & + & - \\
\hline S1063 N [64] & - & + & - \\
\hline D1362 N [64] & - & + & - \\
\hline I734T [61] & + & - & - \\
\hline $\mathrm{CFH}$ & & & - \\
\hline rs6677604 [65, 69-71] & - & $+(\mathrm{SLE}, \mathrm{IgAN})$ & - \\
\hline Y402H (rs1061170) $[12,34,62,65,68]$ & $+(\mathrm{DDD}, \mathrm{C} 3 \mathrm{GN})$ & $+(\mathrm{SLE})$ & - \\
\hline V62I (rs800292) [34, 63-65] & $+(\mathrm{DDD})$ & $+(\mathrm{SLE})$ & - \\
\hline IVS 2-18insTT [34] & $+(\mathrm{DDD})$ & - & - \\
\hline A473A [34] & $+(\mathrm{DDD})$ & - & - \\
\hline p.Lys224del (rs796052138) [102] & + & - & - \\
\hline c.197G > A, p.Cys66Tyr [117] & - & $+(\operatorname{IgAN})$ & - \\
\hline c. $615 \mathrm{~T}>\mathrm{A}[117]$ & - & $+(\operatorname{Ig} \mathrm{AN})$ & - \\
\hline c. $.50 \mathrm{~T}>\mathrm{G}[117]$ & - & $+(\operatorname{Ig} \mathrm{AN})$ & - \\
\hline c2933G > T [117] & - & $+(\operatorname{IgAN})$ & - \\
\hline CFHR & & & - \\
\hline Duplication in CFHR5 gene [75] & + & - & - \\
\hline Duplication in CFHR1 gene [39] & + & - & - \\
\hline CFHR3-1 hybrid gene [76] & + & - & - \\
\hline CFHR2-CFHR5 hybrid gene [40] & + & - & - \\
\hline CFHR5-CFHR2 hybrid gene [77] & + & - & - \\
\hline CFHR1-5 hybrid gene [80] & + & - & - \\
\hline rs16840639 [69] & - & $+(\mathrm{SLE})$ & - \\
\hline CFHR3-1 $\Delta[32,70,71]$ & - & $\begin{array}{l}+ \text { (protective in } \\
\text { IgAN, risk factor in } \\
\text { SLE) }\end{array}$ & - \\
\hline P46S (rs12097550) [34] & $+(\mathrm{DDD})$ & - & - \\
\hline -249T/C (rs9427661) [34] & $+(\mathrm{DDD})$ & - & - \\
\hline$-20 \mathrm{~T} / \mathrm{C}$ (rs9427662) [34] & $+(\mathrm{DDD})$ & - & - \\
\hline IVS1 + 75T/A [34] & $+(\mathrm{DDD})$ & - & - \\
\hline IVS2 + 58C/T [34] & $+(\mathrm{DDD})$ & - & - \\
\hline
\end{tabular}


Table 1 (continued)

\begin{tabular}{|c|c|c|c|}
\hline Mutations & $\mathrm{C} 3 \mathrm{G}$ & $\begin{array}{l}\text { Immune-complex- } \\
\text { mediated GN }\end{array}$ & $\begin{array}{l}\text { Pauci- } \\
\text { immune } \\
\text { GN }\end{array}$ \\
\hline CFB & & & - \\
\hline G161R [64] & - & + & - \\
\hline H451R [64] & - & + & - \\
\hline R679 W [64] & - & + & - \\
\hline p.Glu566Arg [79] & - & + & - \\
\hline \multicolumn{4}{|l|}{$\mathrm{MCP}$} \\
\hline-652 A > G (rs2796267) [62] & + & + & - \\
\hline
\end{tabular}

in a single individual may have a more potent effect on AP regulation and may increase the risk of GN development.

On the other hand, some intronic SNPs, which do not alter molecule structure and function, also show an association with GN. It was proposed that they may 'tag' other, more common SNPs or mutations. As an example, SNP rs6677604 located in an intronic region of $\mathrm{CFH}$ gene has no functional consequence. However, it tags a common copy number polymorphism CFHR3-1 $\triangle$, which confers protection for IgAN, has been shown to be a risk factor for SLE [65, 69-72].

Also, several rare mutations of the AP components have been described in GN patients. Single SLE cases associated with different $\mathrm{C} 3$ mutations have been reported in the Japanese population [73, 74]. Further, first described in patients of Cypriot origin, familial cases of $\mathrm{C} 3 \mathrm{G}$, associated with mutant CFHR proteins, have also been found in patients of other ethnicities [39, 40, 75-78].

At present, there are only a few reports about the role of CFB and MCP mutations in glomerular pathology (Table 1) $[62,64,79]$. Nevertheless, the facts that CFB along with $\mathrm{C} 3$ creates AP C3 convertase and MCP is another vital AP regulator suggest the need for further studies. Although current knowledge on the functional consequences of CFB polymorphisms and mutations is rather limited, functional studies indicate that they may influence the $\mathrm{C} 3 \mathrm{bBb}$ complex formation [28]. In aHUS, genetic abnormalities in CFB are more frequent than in C3G. Some these mutations cause excessive complement activation, resulting in more severe disease with high risk of progression to the end-stage renal disease (ESRD) [80]. The genetic background of AP abnormalities in glomerular diseases will be discussed in detail below.

\section{The role of the alternative pathway of complement activation in glomerular injury}

\section{C3 glomerulopathy}

C3G is a sporadic disease ( 2 per million), which is characterized by predominant glomerular deposits of $\mathrm{C} 3$ in the absence of a significant amount of Ig on immunofluorescence (IF) $[8,10,81]$. Based on electron microscopy (EM), it is further divided into DDD and C3 glomerulonephritis (C3GN). Dense, band-like osmophilic deposits in the GBM on EM and membranoproliferative type of injury on histopathology are typical features of DDD. C3GN, on the other hand, is characterized by subendothelial, mesangial and in some cases subepithelial $\mathrm{C} 3$ deposits on EM. On the light microscopy (LM), $71 \%$ cases of C3GN show membranoproliferative pattern of injury, though mesangial proliferation, crescent formation, and glomerular sclerosis may also occur $[7,8,10,62,67,82,83]$.

\section{Clinical features of C3GN and DDD}

C3GN affects both sexes equally, usually in the third decade of life. Clinically, it manifests with hematuria (63-92\% of cases) or less frequently with nephrotic syndrome (16-27\% of cases). In general, the prognosis in C3GN is very poor with 23\% patients progressing to the ESRD during a median follow-up period of 28 months [ 82,85$]$. DDD is a rare entity usually diagnosed in early childhood, affecting both genders equally $[62,81]$. Clinically, it presents with hematuria (76-89\%) and subnephrotic proteinuria, but acute nephritic or nephrotic syndrome may also occur. In most affected individuals, it leads to ESRD (in approximately half of the patients within 10 years from diagnosis) [81, 84]. Features of (PD), diabetes mellitus type 1, and ocular drusen can accompany DDD, but they have not been reported in C3GN [84]. Drusen are whitish-yellow deposits of lipoproteins and complement components within the ocular Bruch's membrane, beneath the retinal pigment epithelium, which are similar to those seen in AMD. However, in DDD, they have an earlier age of the onset, and they impair vision in approximately $10 \%$ of patients [31]. Interestingly, no correlation between severity of renal and ocular disease has been found. PD is a condition appearing in early childhood, characterized by bilaterally symmetrical loss of subcutaneous facial and upper extremity fat. It is a result of complement activation in the adipose tissue [81]. PD usually precedes the DDD onset, and it has been estimated that approximately $22 \%$ of 
PD patients develop DDD during 8 years from the diagnosis [85].

C3G is characterized by complement dysregulation, meaning that complement may be activated spontaneously, due to acquired or congenital AP proteins abnormalities. The crucial role of AP dysfunction seems to be supported by recent reports of low plasma levels of AP components in C3G patients, such as C3, CFB, and CFH [62]. C3 levels are more often depleted in DDD than in C3GN (59.1 vs. 39.6\%, respectively) [62, 85]. However, C3 plasma concentration within normal range does not exclude AP activation, as local (e.g., renal) $\mathrm{C} 3$ production and subsequent consumption may contribute to the disease pathogenesis [25]. Moreover, studies have shown that $\mathrm{iC} 3 \mathrm{~b}$ is the main constituent of the dense deposits in the GBM. Both CFI and CFH are essential for $\mathrm{C} 3 \mathrm{~b}$ cleavage to $\mathrm{iC} 3 \mathrm{~b}$, but the abnormalities of $\mathrm{CFH}$, not $\mathrm{CFI}$ are responsible for the disease occurrence [9, 83, 87]. This was demonstrated in an animal model, where $\mathrm{CFH}$-deficient mice, which were also deficient in factor I, did not develop DDD but showed C3 mesangial deposition instead [86]. Extensive complement activation in DDD was described in various animal models. A lethal renal pathology, comparable to human MPGNII, with C3 depletion in plasma and increased levels of MAC, was first diagnosed in 10 Yorkshire piglets [87]. Later, CFH deficiency was identified as a cause of complement abnormality leading to the hereditary porcine MPGNII [88]. In more recent studies, mice lacking CFH gene ( $\mathrm{CFH}-/-)$ developed GN characterized by the capillary wall thickening, mesangial cell proliferation, mesangial and capillary staining for $\mathrm{C} 3$ and $\mathrm{C} 9$, and intramembranous dense deposits. Both $\mathrm{CFH}-/-$ and $\mathrm{CFH}-/+$ animals exhibited the evidence of AP dysregulation (low $\mathrm{C} 3$ levels, MAC concentration was not assessed in this study). Remarkably, the heterozygous deficiency was sufficient to impair control of $\mathrm{C} 3$ activation, but it did not cause renal pathology since both $\mathrm{CFH}+/-$ and wild-type mice showed no histological evidence of MPGN. To confirm that the uncontrolled C3 activation causes MPGN in $\mathrm{CFH}-/-$ mice, a second mutation in $C F B$ gene was introduced. Since the lack of $C F B$ hinders the formation of $\mathrm{C} 3$ convertase, mice deficient in both $C F H$ and $C F B$ genes did not show signs of GN [89]. In the next study, mice deprived of both $C F H$ and $C 5$ genes developed less severe GN with significantly reduced mortality, glomerular cellularity, and slower worsening of renal function within 12 months of observation. Although C5 deficiency reduced MAC formation and prevented the formation of $\mathrm{C} 5 \mathrm{a}$, it did not affect the $\mathrm{C} 3$ deposition, which was sufficient to disrupt the permeability of the GBM, resulting in comparable levels of albuminuria in both $\mathrm{CFH}-/-$ and C5-/- mice [90].

The studies performed by Ruseva et al. and Lesher et al. focused on the role of FP in glomerular injury. Since the 1970s, FP has been considered to be the only positive regulator of AP. It binds to $\mathrm{C} 3 \mathrm{bBb}$ and stabilizes it thus counteracting CFH. Based on this knowledge, it has been expected that FP inhibition would ameliorate the AP activation. Conversely, enhancing FP would cause more efficient AP activation. Unexpectedly, studies on murine models, designed to inhibit FP by producing animals deprived of $C F H$ and $F P$ genes [91] or mice lacking the $F P$ gene but producing small amounts of truncated $\mathrm{CFH}\left(\mathrm{CFH}^{\mathrm{m} / \mathrm{m}}\right.$; without SCRs 19-20) [92] showed that the absence of FP exacerbated C3G. Both $\mathrm{CFH}^{\mathrm{m} / \mathrm{m} / \mathrm{P}^{-/-}}$and $\mathrm{CFH}^{-/-} / F P^{-/-}$mice developed severe GN resembling human DDD with predominant $\mathrm{C} 3$ depletion. Notably, there were several differences in clinical presentation between these two strains of mice. The $\mathrm{CFH}^{-/-} / \mathrm{FP}^{-/-}$deficient mice presented with an increased glomerular cellularity, capillary wall thickening with double contours on LM, linear pattern of $\mathrm{C} 3$ deposition on IF, and subendothelial electron dense capillary deposits on EM. The $\mathrm{CFH}^{\mathrm{m} / \mathrm{m}} / \mathrm{FP}^{-/-}$mice developed the even more severe disease since all the animals died. The renal injury in $C F H^{\mathrm{m} / \mathrm{m}} /$ $\mathrm{FP}^{-/-}$was characterized by an intense $\mathrm{C} 3$ deposition along the vascular walls and slightly higher $\mathrm{C} 3$ plasma concentration. According to the authors, low but not entirely depleted $\mathrm{C} 3$ levels caused AP activation. In the absence of $F P$ gene and SCRs 19-20 of $C F H$ gene, AP activation occurred exclusively on GBM and podocytes, resulting in a linear pattern of C3 staining [91, 92]. These studies emphasize the complexity of $\mathrm{C} 3 \mathrm{G}$ pathogenesis. Namely, they imply the possibility of the contribution of more than one genetic abnormality in the development of the disease and its clinical phenotype.

It remains unclear why some patients present with DDD and the other with C3GN. Also, the exact trigger of AP dysregulation is unidentified. Some authors are seeking the answer in the frequent prevalence of monoclonal Ig deposition along with $\mathrm{C} 3$ and high frequency of plasma monoclonal Ig in $\mathrm{C} 3 \mathrm{G}$ patients (approximately $31 \%$ of cases diagnosed with C3GN and 71\% of DDD cases) [93, 94]. An assumption that monoclonal Ig acts as autoantibody activating the AP has been made [82, 83]. Using in situ hybridization, Elfituri et al. found monoclonal kappa light chain plasma cells infiltrating the glomeruli of an 11-year-old C3GN patient, who had no monoclonal Ig in plasma and normal serum and urine electrophoresis pattern. Based on these findings, the authors hypothesized that monoclonal Ig might be the direct cause of $\mathrm{C} 3$ deposition [83].

\section{Acquired AP abnormalities in C3G}

Most cases of $\mathrm{C} 3 \mathrm{G}$ are acquired and associated with different types of autoantibodies against the AP components (Table 2). The autoantibody against the C3 convertase termed $\mathrm{C} 3$ nephritic factor $(\mathrm{C} 3 \mathrm{NeF})$ is present in sera of $40 \%$ cases of $\mathrm{C} 3 \mathrm{GN}$ and approximately $80 \%$ of 
Table 2 Acquired factors predisposing to the AP-related glomerular diseases

\begin{tabular}{llll}
\hline Autoantibodies & C3G & $\begin{array}{l}\text { Immune- } \\
\text { complex } \\
\text { GN }\end{array}$ & PMN \\
\hline anti-C3bBb (C3NeF) [34, 62, 68, 147] & + & + & + \\
anti-C3bBbC3b (C5Nef) [98] & + & - & - \\
anti-C3 [73, 126] & - & $+(\mathrm{LN})$ & - \\
anti-C3b [95, 127] & + & $+(\mathrm{LN})$ & - \\
anti-CFH [68, 73, 99] & + & + & - \\
anti-CFB [73, 95] & + & + & - \\
anti-CFI [73] & - & + & - \\
anti-FP [73] & - & + & - \\
\hline
\end{tabular}

DDD patients [34, 62]. It has also been found in carriers of $\mathrm{CFH}$ mutations (about $54 \%$ of cases), as well as in healthy individuals $[62,67]$. The triggers leading to the production of these autoantibodies are unknown. C3Nef activity is heterogeneous, depending on the stabilization of $\mathrm{C} 3$ convertase by $\mathrm{C} 3 \mathrm{Nef}$ only ( $\mathrm{FP}$ independent) or by both C3Nef and FP (FP-dependent C3Nef). All types of $\mathrm{C} 3 \mathrm{Nefs}$ by binding to a neoepitope on $\mathrm{C} 3 \mathrm{bBb}$ slow down the dissociation of $\mathrm{Bb}[31,95]$. As a result, the time of $\mathrm{C} 3$ convertase activation is prolonged, and it becomes resistant to the AP-regulating factors. Clinically, low levels of circulating $\mathrm{C} 3, \mathrm{C} 3$ split products $(\mathrm{C} 3 \mathrm{dg} / \mathrm{C} 3 \mathrm{~d}), \mathrm{C} 3$ deposits on IF and positive hemolytic assay are observed [34, 68, 82]. However, the activation of MAC occurs only when C3 convertase is stabilized by both C3Nef and FP [96, 97]. In a recent study, Marinozzi et al. [98] have shown a more detailed insight on the association between FP and autoantibodies to AP components. The authors found $\mathrm{IgG}$ to $\mathrm{C} 5$ convertase (called C5Nef) in $49 \%$ of $\mathrm{C} 3 \mathrm{G}$ cases and C3Nef in $68 \%$ of cases, including $39 \%$ patients positive for both $\mathrm{C} 3$ and C5Nefs. In this study, C3Nef correlated with low C3 plasma levels, but in most cases (62\%) MAC levels remained below the normal range. The occurrence of C5Nef was related to both $\mathrm{C} 3$ consumption and high MAC levels. According to the authors, binding of FP to $\mathrm{C} 3 \mathrm{bBb}$ stabilizes $\mathrm{C} 5$ convertase rather than $\mathrm{C} 3$ convertase. The prevalence of C5Nef was higher in $\mathrm{C} 3 \mathrm{GN}$ (72\%), while C3Nef was more frequent in DDD (71\%), suggesting that the type of nephritic factors may determine the biological phenotype of C3G [98]. These results are consistent with the previously described role of FP in animal models deficient in $\mathrm{CFH}$ gene, where coexisting FP deficiency was associated with $\mathrm{C} 3$ depletion, whereas plasma $\mathrm{C} 5$ depletion was (at least in part) FP-dependent [91, 92]. In $\mathrm{CFH}^{-/-}$mice, $\mathrm{FP}$ also influenced the intraglomerular distribution of $\mathrm{C} 3$, since only these mice injected with human $\mathrm{CFH}$ presented $\mathrm{C} 3$ mesangial deposition, while
$\mathrm{CFH}^{-/-} / \mathrm{P}^{-/-}$mice did not show mesangial C3 staining [91].

Other autoantibodies such as anti-CFH, anti-C3b, and anti-CFB have been found in patients with C3G [68, 95]. Various autoantibodies have different mechanisms of AP dysregulation. The anti-CFH antibody is directed precisely to the N-terminal end of CFH (SCR 1-4), resulting in the loss of CFH regulation in plasma [95, 99]. C3Nef frequently coexists with anti-CFH, possibly having a synergistic effect on AP dysregulation in plasma. In a single report, anti-CFH was also associated with monoclonal Ig (35\% cases in the small group of 17 patients), which is in line with previous reports of monoclonal Ig pathogenic involvement in $\mathrm{C} 3 \mathrm{G}$ [82, 83, 99].

Anti-CFB by binding to a neoepitope in native CFB or its activated form $\mathrm{Bb}$ enhances not only $\mathrm{C} 3$ convertase activation but also affects terminal pathway by blocking C5 convertase. Marrinozi et al. reported an association between anti-C3b/anti-CFB and infections. According to the authors, this may be explained by the similarities in coding sequences between $\mathrm{C} 3$ and certain pathogens (Streptococcus epidermidis, Streptococcus capitis, Klebsiella pneumoniae, Shigella flexneri) [95]. Altogether, these data indicate that autoantibodies alone may not be sufficient to trigger the disease onset. In most cases, additional factors such as the environmental or genetic abnormalities or the combination of all causes mentioned above may lead to the development of the disease. Undoubtedly, it is essential to investigate the potential risk factors further, as it may be crucial for future diagnostic and treatment recommendations.

\section{Hereditary AP abnormalities in C3G}

Although less common, genetic defects of the AP components, alone or in combination with the other, currently not well-defined factors, may contribute to $\mathrm{C} 3 \mathrm{GN}$ development. McLean et al. [52] in a small study (only nine patients) reported a higher frequency of a $\mathrm{C} 3 \mathrm{~F}$ allele in patients diagnosed with MPGN II. Finn et al. supported this observation in a study of 26 cases with presence of $\mathrm{C} 3 \mathrm{NeF}$ and MPGN II or PD, where the prevalence of C3F allele was significantly higher [51]. Recently, in one familial case of $\mathrm{DDD}$, a heterozygous pathogenic variant of the $C 3$ gene coded a mutant $\mathrm{C} 3(\Delta \mathrm{DG} 3923)$ protein, which was resistant to cleavage by the $\mathrm{C} 3$ convertase. This led to a constant production and consumption of $\mathrm{C} 3$ coded by normal allele and subsequent alternative pathway dysregulation in a fluid phase [100]. However, in a single report of a familial C3GN in the French cohort, a cell surface AP dysregulation was described. The two affected individuals carried the mutation in $C 3$ gene (p.I734T), located in the binding region for CFH and CR1, which caused the functional deficiency of $\mathrm{CR} 1$ and $\mathrm{CFH}$. The authors speculate that an impairment of 
the surface-bound AP regulation may be associated with a C3GN phenotype, whereas fluid-phase dysregulation with DDD presentation [61]. Chen et al. reported another heterozygous mutation in the $C 3$ gene (c.C1774T/p.R592W) in a patient with $\mathrm{C} 3 \mathrm{GN}$ combined with TMA and subacute tubulointerstitial nephritis. Interestingly, the patient's brother who was not the carrier of this mutation developed atypical hemolytic syndrome (aHUS) [101]. In a recent study, performed by Iatropoulos et al. on a group of $71 \mathrm{C} 3 \mathrm{G}$ cases, mutations in the AP components (C3,CFI, CFH, and $M C P$ ) were significantly more common in a $\mathrm{C} 3 \mathrm{G}$ group than in controls. Fifty percent of all reported genetic abnormalities were located in the regulatory domains of the $C 3$ gene and included the following mutations: V619 M, R1042Q, R1303H, R13200Q, C1518R, and D1625H. A novel mutation in the thrombomodulin gene (THBD A473 V; rs 1042579) was also described. Though the authors underlined that the cumulative effect of the homozygous risk variants V62I in $C F H$ (rs800292) and A473 in THBD (found in $58 \%$ of $\mathrm{C} 3 \mathrm{G}$ patients) together with the presence of one of the above-mentioned mutations in $C 3$ gene, but not the single $C 3$ variation alone, was associated with a significant risk for $\mathrm{C} 3 \mathrm{G}$ development [64].

An association between an SNP in the $M C P$ gene (- 652 A > G; rs2796267) and C3G was reported by Servais et al. The authors also described a risk haplotype of combined MCP mutations (-652A, -366A, IVS9-78G, IVS12 + 638G, c.2232T) [62].

As mentioned earlier, since the GBM lacks membranebound AP regulators, it depends exclusively on CFH inhibiting properties, by binding and absorbing CFH. It is consistent with the fact that some $\mathrm{CFH}$ mutations confer risk for DDD. A well-known mutation in $\mathrm{CFH}$ gene, associated with AMD, (c.1204T > C; Y402H; rs1061170), was also reported in DDD patients by Abrera-Abeleda et al. [34]. The protective variant (Y402Y) of rs1061170 bound with a stronger intensity to CRP and heparin than the risk variants $(\mathrm{H} 402 \mathrm{Y}$ and $\mathrm{H} 402 \mathrm{H}$ ). However, there was no difference in binding to $\mathrm{C} 3 \mathrm{~b}$ between these three genotypes [66]. Later, this observation was confirmed by Servais et al. [62] in a group of 27 patients. Sethi et al. [68] in a study of small group (5 C3G patients, including 1 with DDD, 3 with C3GN, and 1 case with microscopic features of both diseases) confirmed the AP activation (measured by MAC deposits in glomeruli) and prevalence of at least one copy of $\mathrm{H} 402$ allele in both DDD and $\mathrm{C} 3 \mathrm{GN}$ patients. Other specific allele variants in the $\mathrm{CFH}$ gene (V62I/rs800292, IVS 2-18insTT, A473A) and in the CFHR5 gene (P46S/rs12097550, -249T/C/rs9427661, $-20 \mathrm{~T} / \mathrm{C} / \mathrm{rs} 9427662$, IVS $1+75 \mathrm{~T} / \mathrm{A}, \mathrm{IVS} 2+58 \mathrm{C} / \mathrm{T})$ are considered to be associated with DDD [34]. The 62I variant of rs800292 confers protection against C3G, aHUS, and $\mathrm{AMD}$, as it has a stronger ability to $\mathrm{C} 3 \mathrm{~b}$ binding and thus enhances the CFH-dependent AP inhibition both in fluids and on the cell surfaces [63]. Conversely, the V62 variant allele of rs800292 is less efficient at inactivating $\mathrm{C} 3 \mathrm{~b}$, and it is a susceptibility allele for $\mathrm{C} 3 \mathrm{G}$, aHUS and AMD [64]. Aberera-Abeleda et al. described the additive cumulative risk of C3F/S (R102G; rs2230199) and HAV4$1+/-(\mathrm{P} 314 \mathrm{~L}$; rs1047286) SNPs of the $C 3$ gene together with the $C F H$ SNP Y402H (rs 1061170) for the development of DDD. The presence of at least one copy of the both $C 3$ G102 (C3 F) and C3 L314 (HAV4-1+) causes stronger affinity of $\mathrm{C} 3$ binding to $\mathrm{CFB}$, while the $\mathrm{CFH} \mathrm{H} 402$ allele shows an impaired $\mathrm{C} 3 \mathrm{~b}$ binding that finally results in enhancing the $\mathrm{C} 3$ convertase activity and an uncontrolled consumption of the AP components [50]. Habbig et al. presented two female siblings (12 and 7 years old) with the deletion of 224 lysine in rs 796052138 , located in the $\mathrm{N}$-terminal end of CFH (SCR-domain 4), affected by a renal disease compatible with $\mathrm{C} 3 \mathrm{G}$. Both children were $\mathrm{C} 3 \mathrm{NeF}$ positive, had low plasma $\mathrm{C} 3$ and $\mathrm{CFB}$ levels, and were successfully treated with chronic infusion of fresh frozen plasma [102].

Several cases of the familial C3G have been described to be associated with various mutations in the $C F H R$ gene cluster. Gale et al. in Cypriot families reported a disease, which clinically presented with synpharyngitic hematuria, renal failure, and $\mathrm{C} 3 \mathrm{G}$ features on biopsy. All affected individuals had an internal duplication of exons 2 and 3 in CFHR5 gene, resulting in an expression of the mutant CFHR5 protein, with reduced affinity for the surface-bound complement. This new entity was called CFHR5 nephropathy, and it was classified as a subtype of C3G $[7,75]$. Other cases of C3G associated with mutant CFHR proteins have been described. For instance, the novel mutant multimeric CFHR1 protein that showed enhanced competition with $\mathrm{CFH}$ was a result of an intragenic duplication in N-terminal SCRs of CFHRI gene. The dysregulation of complement was present only on the certain surfaces, but (according to the authors) probably did not occur on the endothelium, explaining the $\mathrm{C} 3 \mathrm{G}$ and not aHUS onset [39]. Malik et al. [76] reported a unique hybrid CFHR3-1 gene, which caused a familial C3G. The authors speculate that this new gene interferes with $\mathrm{C} 3$ regulation by $\mathrm{CFH}$ and CFHR5, resulting in uncontrolled $\mathrm{C} 3$ activation and its accumulation in the kidney. Chen et al., in familial cases of two DDD patients, discovered a chromosomal deletion in $C F H R$ gene cluster that led to the expression of a hybrid CFHR2-CFHR5 plasma protein. The fusion protein favored the $\mathrm{C} 3$ convertase formation by recruiting $\mathrm{P}$ and competing with $\mathrm{CFH}$ for binding to $\mathrm{C} 3 \mathrm{~b}$ [40]. Xiao et al. reported another hybrid gene, CFHR5-CFHR2, in two relatives diagnosed with $\mathrm{C} 3 \mathrm{G}$. The novel hybrid CFHR5CFHR2 protein facilitated the formation of large multimers of CFHR1, CFHR2, and CFHR5, which antagonized CFHdependent AP regulation [77]. Similarly, the mutant CFHRI5 hybrid gene found in four family members diagnosed with $\mathrm{C} 3 \mathrm{G}$ also exhibited the enhanced inhibition of $\mathrm{CFH}$. As the 
evidence of both $\mathrm{C} 3$ and $\mathrm{C} 5$ dysregulation, all affected individuals had low $\mathrm{C} 3$ and $\mathrm{FB}$ levels and increased MAC and $\mathrm{Bb}$ plasma concentration. Also, in two patients, complete CFHR1 deficiency due to CFHR3-1 $\Delta$ was observed. Unlike the above-mentioned hybrid proteins, mutant $C F H R I-5$ was created as a result of a genetic rearrangement of 3 CFHRs genes, namely the heterozygous 147-kilobase deletion, spanning from CFHR 1 intron 4 to the $5^{\prime}$ region of CFHR5 [78]. Altogether, the exact pathogenic mechanism by which the genetic abnormalities in CFHRs cause the disease is still unknown, but likely involves deregulation of the CS. Nevertheless, further studies are required to assess the exact role of CFHRs in the AP-mediated renal injury.

\section{C3G versus aHUS}

Finally, certain similarities, such as involvement of the AP, frequent prevalence of anti-FH antibodies, and reasonable response to the treatment with eculizumab raise a question whether $\mathrm{C} 3 \mathrm{G}$ and aHUS are separate diseases or just the two sides of the same coin $[15,103]$. In general, mutations in the C3 gene are uncommon in $\mathrm{C} 3 \mathrm{G}$, and they are more likely to be associated with DDD rather than $\mathrm{C} 3$ glomerulonephritis (C3GN) phenotype [61, 62]. In contrast, genetic abnormalities in $C 3$ gene occur more often in aHUS [104].

In $\mathrm{C} 3 \mathrm{G}$, complement dysregulation is due to $\mathrm{CFH}$ dysfunction in a fluid phase, resulting in a systemic AP activation and $\mathrm{C} 3$ fragments deposition in the kidney. Conversely, CFH surface-bound regulation is impaired in aHUS. Uncontrolled activation of complement occurs here directly on glomerular and microvascular endothelium, and it is responsible for the development of TMA and hemolysis of erythrocytes, without deposition of the AP components in glomeruli $[10,105]$. Notably, overt thrombosis is not always seen in aHUS biopsy samples. In line with this, the KDIGO 2017 consensus report suggests referring to aHUS as a 'microangiopathy,' with the term thrombotic being reserved for the cases with proven thrombosis. The KDIGO 2017 consensus underlines that the boundary between those diseases in some cases may be very subtle, and some patients may present with both entities [106]. The 'two-hit' model for endothelial activation in TMA has been proposed, in which the endothelium can change its properties from preferential synthesis of vasodilators and antithrombotic molecules to production of vasoconstrictors and prothrombotic mediators. In the presence of pathogenic mutations and autoantibodies, this 'primary beneficial response,' aimed to protect the host against the aggression (e.g., infection with a pathogen) may lead to uncontrolled complement activation and excessive inflammation with microvascular thrombus formation. The local AP dysregulation on the endothelial cells seems to be crucial for aHUS pathogenesis, but the particular susceptibility of the glomerular endothelium is poorly understood.
One possible explanation may lay in the heterogeneous pattern of expression of the different hemostatic mediators on various types of the endothelium (including glomerular endothelium), as well as the tissue-restricted production of distinct structures of the GAG, which can bind to CFH. Conversely, in $\mathrm{C} 3 \mathrm{G}$, systemic $\mathrm{C} 3$ activation seems to cause AP dysregulation without the involvement of the glomerular endothelium. It is not clear, why the increased production of anaphylatoxins (C3a and C5a) does not cause endothelial injury and why high levels of circulating $\mathrm{C} 3 \mathrm{~b}$ does not locally activate the AP on the endothelium in this disease [107]. This underlies the importance of abnormalities concerning the C-terminal end of CFH protein (SCR 19-20), which in physiological conditions regulates surface-bound $\mathrm{C} 3 \mathrm{bBb}$, for the occurrence of aHUS (Fig. 3). In fact, autoantibodies to the C-terminal end of $\mathrm{CFH}$ are found in approximately $10 \%$ of aHUS patients, and the majority of them have a homozygous deletion of CHFR1 [37, 108, 109]. Furthermore, the prevalence of anti-CFH antibodies correlates with the occurrence of CFHR3-1 $\triangle$ variant, known to be protective against IgAN and AMD, and a risk factor for SLE and aHUS [47, 70, 83]. The exact impact of the same mutation being protective in some diseases and predisposing to the other remains to be specified. In case of AMD, one possible explanation is the complement deregulation caused by the absence or deficiency of either CFHR1 or CFHR 3 or both these proteins [37]. Mutations located in the $\mathrm{N}$-terminal end (SCR 1-4) or autoantibodies against this part of CFH influence the $\mathrm{C} 3 \mathrm{~b}$ and $\mathrm{C} 3$-convertase binding in plasma and most of them are responsible for the development of $\mathrm{C} 3 \mathrm{G}$ (Fig. 3) $[10,25,104]$. However, in the recent studies, some N-terminal genetic abnormalities in $C F H$, as well as anti-CFH antibodies to SCRs1-4, have also been reported in aHUS. Moreover, the same mutations in $C F H$ and $C F I$ have been found in both diseases, indicating that genetic abnormalities or the presence of autoantibodies are not sufficient to determine the disease phenotype. In most aHUS patients, an underlying complement abnormality is not enough to trigger the disease. The additional genetic and environmental or still unknown factors drive the patients toward one or another condition, or they remain disease-free despite the presence of gene abnormality $[62,100,106,107]$. The detailed role of the AP abnormalities in the pathogenesis of aHUS (due to its complexity) is currently prepared as a separate article.

\section{Immune-complex glomerulonephritis}

Immune-complex GN is a group of diseases, in which circulating and locally deposited immune complexes activate complement. As the result of this activation, IF confirms polyclonal Ig, complement components and MAC deposition in glomeruli. On LM, the pattern of injury may vary from mesangial proliferative, membranoproliferative, and 
extracapillary proliferative lesions with the addition of exudative, necrotizing, and sclerotic changes. In some cases, mixed membranous and proliferative pattern could be observed. According to the new classification, several distinct disease entities, such as primary membranoproliferative glomerulonephritis type I and type III (MPGN I, MPGN III), IgAN, and lupus nephritis (LN) have been included in this category $[7,8]$. The activation of immune complexes by the $\mathrm{CP}$ led to the assumption that other complement pathways are not involved in the disease pathogenesis. However, glomerular co-deposition of CFHR5, CFH, and FP has been found in MPGN I, LN and IgAN cases, indicating the AP involvement in these diseases [7, 8, 32, 110, 111]. In MPGN I patients, Servais et al. reported low AP proteins levels, such as C3, CFB, CFH, and CFI (in 46.3, 34.1, 4.9, and 7.3\% of cases, respectively) and the prevalence of the $\mathrm{C} 3 \mathrm{NeF}$ (in $53.6 \%$ cases), what suggested the AP activation [62]. In the other studies, anti-C3b, anti-CFB, and anti-CFH antibodies have been found in Ig-MPGN patients (Table 2) [95, 99]. Recent reports have also shown that genetic abnormalities of the AP proteins may be present in immune-complex GN (Table 1). The candidates are $C F B$ gene (G161R, H451R and R679 W), C3 gene (V86I, R505C, G637R, K1051M, S1063N, D1362N) and $M C P$ gene mutations $(-652 \mathrm{~A}>\mathrm{G}$; rs2796267) [62, 64]. For instance, a heterozygous variant, p.Glu566Arg, in the exon 13 of the $C F B$ gene has been reported to be associated with immune-complex-mediated GN in a case report of a 7-year-old boy. This patient was successfully treated with eculizumab, a monoclonal antibody targeting $\mathrm{C} 5$ and consequently inhibiting MAC formation [79].

\section{$\lg A N$}

IgAN is the most common form of glomerulonephritis worldwide. As an immune-complex-mediated GN, it is associated with glomerular immune complexes containing aberrant IgA1, activating the AP or LP. On renal biopsy specimens, components of the $\mathrm{CP}$ (such as $\mathrm{C1q}$ ) are absent [7, 32, 112]. Instead, mesangial deposits of C3, CFHR5, $\mathrm{CFH}$, and $\mathrm{P}$ are found on IF together with low $\mathrm{C} 3$ plasma concentrations [110]. Whether the AP is activated by circulating IgA1-containing immune complexes or after their deposition in the mesangium is yet to be determined [32]. Nevertheless, Zhu et al. proposed systemic complement activation after having found higher C3 kidney deposition in patients with low circulating C3 levels. Surprisingly, and on the contrary to previous reports, results of a recent study revealed no correlation between decreased serum C3 levels and renal progression [70]. Rambausek et al. have shown a higher frequency of $\mathrm{C} 3 \mathrm{FF}$ and lower of $\mathrm{C} 3 \mathrm{~F} / \mathrm{S}$ alleles in IgAN patients compared to controls (10.4 vs. 3.4 and 19.4 vs. $35.8 \%$, respectively). Of note, C3FF carries showed a faster progression to ESRD and much more frequently developed hypertension [54]. Opposite results were obtained by Finn et al. in a Hong Kong Chinese population. Despite the known high prevalence of IgAN in Asians, the frequency of C3F allele was sporadic in their study [53, 113, 114]. Additionally, among 26 patients who had been tested for HAV4-1+/- polymorphism, all were HAV4-1-homozygotes. The authors conclude that in Chinese population other factors than $\mathrm{C} 3$ polymorphism contribute to the pathogenesis of IgAN [53].

Interestingly, according to the recent reports, mutations in the AP-regulating proteins, resulting in a more efficient C3 convertase inhibition, may confer protection against the disease. Indeed, a common copy number polymorphism resulting in the deletion of both $C F H R 3$ and $C F H R I$ genes (CFHR3-1 $\triangle$ ) has been proven to protect from the development of IgAN. As CFHR1 and CFHR3 compete with CFH for the binding site on $\mathrm{C} 3 \mathrm{~b}$, they diminish $\mathrm{C} 3$ convertase dependent decay and C3b inactivation (Fig. 5). Deletion of one or both genes results in lower concentration (in case of homozygous deletion) or absence of CFHR1 and CFHR3 proteins and enhances AP inactivation [32]. Also, the GWAS selection identified minor allele, rs6677604-A in an intron

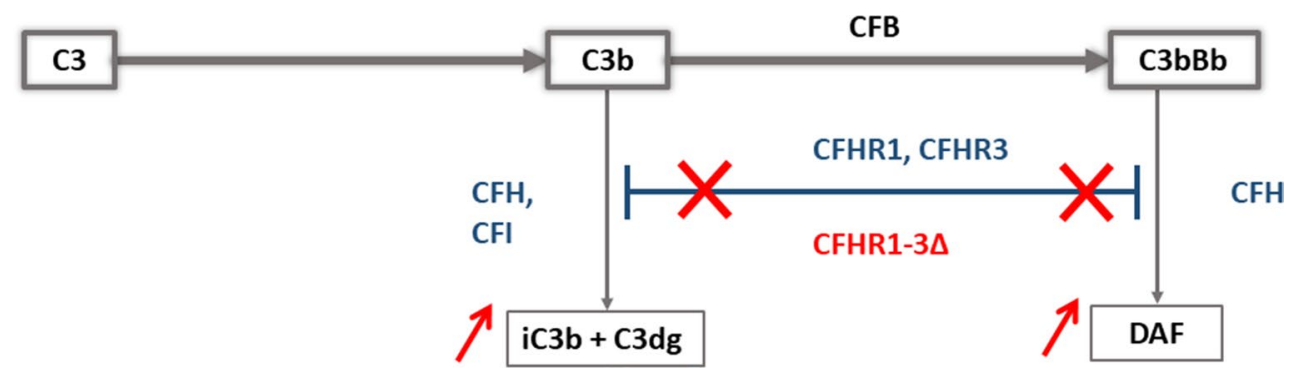

Fig. 5 The function of CFHR3-1 $\Delta$, which confers protection against IgAN and AMD, at the same time being a risk factor for SLE. CFHR1 and CFHR3 due to the presence of SCR 19-20 compete with $\mathrm{CFH}$ for the binding site on $\mathrm{C} 3 \mathrm{~b}$. In contrast to $\mathrm{FH}, \mathrm{CFHR} 1$ and CFHR3 do not possess SCRs 1-4 and cannot, therefore, cleave C3b into inactive split products. In case of CFHR3-1 $\Delta$, CFH more efficiently binds to $\mathrm{C} 3 \mathrm{~b}$, resulting in more potent inhibition and decay of the $\mathrm{C} 3$ convertase. $D A F$ decay accelerating factor. The diagram was based on Maillard et al. [32], modified 
region of the $C F H$ gene, which tagged CFHR3-1 $\Delta$ and conferred protection against IgAN [70, 71]. In a study performed by Zhu et al., among five healthy individuals with rs6677604-AA genotype, four had homozygous CFHR3-1 $\Delta$, and one was heterozygous for CFHR $1 \Delta$. Conversely, both 41 patients and 28 healthy controls with rs6677604-GG genotype carried two copies of $C F H R 1$ and $C F H R 3$ genes, and $90 \%$ of rs6677604-AG heterozygotes (39 patients and 49 controls) were also heterozygous for $C F H R 3-1 \Delta$ [70]. It has been estimated that the deletion of one CFHR3-1 allele reduced the disease risk by $26 \%$, while the absence of two alleles decreased the disease risk by $45 \%$ [72]. However, the rs6677604-A allele was not associated with clinical outcomes, but with a reduced mesangial $\mathrm{C} 3$ deposition, high serum $\mathrm{CFH}$, and low complement $\mathrm{C} 3 \mathrm{a}$ levels [70]. Consistent with this, in the recent retrospective cohort study on Caucasian population, the occurrence of CFHR3-1 $\Delta$ did not correlate with the disease severity, but it was associated with a reduced level of glomerular immune deposits [115]. In general, these reports indicate low CFHR1 and CFHR3 to be protective against IgAN, but they are not sufficient to be used as prognostic markers in IgAN.

In this context, the most recent studies are focusing on finding possible markers for the risk of disease development and its clinical progression [116, 117]. For instance, Medjeral-Thomas et al. in a cohort of 294 IgAN patients demonstrated elevated levels of circulating CFHR1 and CFHR5 proteins in the group with a progressive IgAN. Plasma CFHR1 levels correlated negatively with a decline in glomerular filtration rate, while higher CFHR5 levels were associated with a lack of response to immunosuppression, the presence of endocapillary hypercellularity, and histology scores of disease severity. According to the authors, CFHR1 and CFHR5 proteins compete with CFH to inhibit the AP activation on surfaces in a process called $\mathrm{CFH}$ deregulation. Higher concentrations of these proteins may impair CFH and, thus, predispose to the development of IgAN [116]. Tortajada et al. independently confirmed the role of the competition between $\mathrm{CFH}$ and CFHR1 in the pathogenesis of IgAN [117]. In a group of $112 \operatorname{IgAN}$ patients and 46 patients with a disease unrelated to complement activation (autosomal dominant polycystic kidney disease, ADPKD), the CFHR1 levels and the CFHR1/CFH ratios were elevated in comparison with the 76 controls. Notably, both IgAN and ADPKD patients had highest CFHR1/CFH ratios, but CFHR3-1 $\Delta$ homozygotes were protected only from IgAN and not from ADPKD. The authors conclude that higher CFHR1/CFH ratios and elevated CFHR1 levels correlated positively with a decline in renal function. Interestingly, only twenty one of IgAN cases had low or close to below cutoff values of serum CFH. Out of them, five patients with low $\mathrm{CFH}$ were carries of the novel $\mathrm{CFH}$ (four cases) or $C F I$ (one individual) pathogenic variants. The two mutations in the
CFH gene, namely c.197G > A, p.Cys66Tyr and c.615T > A resulted in a partial $\mathrm{CFH}$ protein deficiency. The functional consequence of the third mutation, c.50T $>\mathrm{G}$ is yet to be determined. Finally, the last of the newly described $\mathrm{CFH}$ mutations c2933G > T was associated with both $\mathrm{CFH}$ and $\mathrm{C} 3$ decreased levels in the studied IgAN individual and this subject' relatives [117]. Although the CFH levels in IgAN patients are in most cases normal, its activity seems to be decreased due to the competition with various CFHRs. Thus, elevated CFHR1, CFHR1/CFH ratio, and possibly CFHR5 may become the new risk markers of IgAN progression to the ESRD.

\section{Lupus nephritis}

LN is a severe complication of SLE affecting approximately $50 \%$ of SLE cases (in 5 years from SLE diagnosis) and worsens the prognosis of the disease [118, 119]. The clinical symptoms of LN include proteinuria (of nephrotic range in $50 \%$ of patients), hematuria (occurring in $80 \%$ of cases), hypertension and a decline in renal function. In $40-60 \%$ of patients, impairment of renal function is stated on diagnosis, and in $10-25 \%$ of them, the disease progresses to ESRD. There is an ample of evidence confirming kidney involvement in a very early stage of SLE (even in the absence of clinical symptoms), and the occurrence of low-level proteinuria and hematuria may be associated with significant renal disease [118-120]. Typically, LN is linked with the $\mathrm{CP}$ of complement activation by circulating immune complexes and autoimmunity directed to the components of the CP $[112,118,119,121,122]$. Growing evidence indicates that the AP takes part in the LN pathogenesis. Decreased serum $\mathrm{C} 3$ levels, frequently observed in $\mathrm{LN}$, are associated with complement over-activation and seem to determine a worse renal prognosis [123]. In a retrospective study of 39 patients with active $\mathrm{LN}$, the prevalence of low $\mathrm{C} 3$ plasma concentration was related to a higher relapse rate and the progression of renal disease [124]. Of note, a positive correlation between low $\mathrm{C} 3$ and clinically silent, but morphologically active juvenile LN has been reported [120]. Recently, Song et al. have described significantly decreased plasma $\mathrm{C} 3$ concentrations and increased $\mathrm{Bb}, \mathrm{C} 3 \mathrm{a}, \mathrm{C} 5 \mathrm{a}$, and MAC levels in patients with active $\mathrm{LN}$. The plasma $\mathrm{Bb}$ levels (but not C3) were associated with $\mathrm{LN}$ outcome and strongly correlated with MAC levels. Also, Bb co-localized with MAC in the glomeruli with LN. The above findings suggest that the activation of MAC in LN reflects mostly the AP consumption [125].

To date, the autoantibodies against $\mathrm{C} 3$ and $\mathrm{C} 3 \mathrm{~b}$ have been reported in LN (Table 2) [126, 127]. In the Bulgarian population, anti-C3 antibodies were present in $31 \%$ of patients (in 12 of total 39 individuals), and they correlated positively with anti-dsDNA antibodies levels, as well as with 
the severity of LN. These antibodies were shown to bind to immobilized $\mathrm{C} 3$ and $\mathrm{C} 3 \mathrm{~b}$. In the serum samples positive for anti-C3 antibodies, the levels of $\mathrm{C} 3$ were significantly lower, compared with the negative samples. The authors speculate that anti-C3 antibodies enhance $\mathrm{C} 3$ convertase, resulting in a more efficient C3 cleavage [126]. In another study, antibodies against $\mathrm{C} 3 \mathrm{~b}$, although less frequent than that against C1q, showed a higher specificity for LN, particularly for the prediction of renal flare [127]. Thus, $\mathrm{Bb}$ and anti-C3b antibodies appear as new markers for monitoring $\mathrm{LN}$ activity $[125,127]$.

In the context of low plasma C3 in LN, Nozal et al. have recently described a case with a 16-years' long history of LN and persistently low serum C3 concentration, independently of flare (two nephrotic flares with 5-years' interval) or remission. The patient and her mother (clinically healthy, but with persistently low C3 level, although higher than in her daughter) carried a heterozygous mutation in the exon 2 of the $C 3$ gene (c.131_146del; p.Leu44Argfs*19). This mutation caused a premature stop, being responsible for the production of non-functioning protein. Notably, antibodies against $\mathrm{C} 3$, CFI, CFB, and FP enhancing the AP activation in the fluid phase were found in this patient's serum [73]. At this point, a question arises if hereditary C3 deficiency can solely predispose to the development of SLE. In Japanese case report of a 22-year-old male, who suffered from photosensitivity, recurrent fever and facial erythema from childhood, and had to be hospitalized due to tonsillitis and recurrent pneumonia in his late teens, the diagnosis of SLE was made at the age of 20 . He was found to be a carrier of a homozygous $\mathrm{C} 3$ deficiency due to the splice acceptor site mutation in intron 38 (C3, IVS38AS, A-G) with undetectable serum C3 [74]. However, his later fate remained unknown. A homozygous mutation (Tyr1081Ter) in the $C 3$ gene resulting in a deficient serum $\mathrm{C} 3$, reported in two Japanese sisters, who developed SLE-like symptoms (a high fever, butterfly rash, Raynaud phenomenon, intermittent arthralgia, and photosensitivity) at their adolescences was mentioned earlier [58]. The study on the largest patients' group of Japanese descent consisting finally of 509 SLE cases and 695 controls revealed that the rs $7951 \mathrm{~T}$ allele was associated with a significant risk of SLE, including LN [59]. In 87 of these patients, serum C 3 level was determined. The mean serum C3 level in carriers of the rs7951 T allele $(n=33)$ was significantly lower compared to non-carriers of the T allele $(n=54)$, although there were no statistical differences in anti-DNA antibody titers, the incidence of renal or central nervous system (CNS) involvement, as well as the daily prednisolone doses between these subgroups [59]. The authors suggest that $\mathrm{C} 3$ heritability predisposes to the development of SLE in the Japanese population. Later, the C3 heritability and the association of genotype with serum C3 were studied in a cohort of 1371 individuals from 393
UK Caucasian SLE families. Also, the relationship of the C3 genotype with SLE was examined in an extended cohort of 2211 individuals from 585 UK Caucasian SLE families [60]. These authors confirmed the link between rs7951 and a lower serum $\mathrm{C} 3$ but found no disease association in the Caucasian population. In their study, the most robust relationship with the serum C3 was observed for SNP rs344555 $(\mathrm{G}>\mathrm{A})$, located in an intron 37. The rare allele of this SNP was associated with higher level of serum C3. However, a different variant (which was not tested in the Japanese study) accounted for the susceptibility to SLE. The disease-associated SNP, rs3745568, was found in intron 27, in a haplotype block encompassing the central region of $\mathrm{C} 3$. Remarkably, no association between rs 3745568 and serum $\mathrm{C} 3$ could be shown. According to the authors, it is likely that genetic variations in the distal end of the $C 3$ gene influence its serum level, while those located in the central region of the gene predispose to the occurrence of SLE [60].

An animal model demonstrated CFH-deficient lupusprone mice which developed syndromes of $\mathrm{LN}$ and subsequent renal failure [128]. A large GWAS carried out on different ethnic groups identified two SLE susceptibility SNPs in the $C F H$ gene: an intronic rs6677604 and an intergenic rs16840639 between $C F H R 1$ and CFHR4. Surprisingly, previously mentioned $C F H R 3-1 \Delta$ variant, protective against IgAN, was associated with increased risk for SLE. An exact way, by which the same mutation predisposes to one disease and protects against another, is still elusive [69]. However, the correlation between CFHR1 and CFHR3 deficiency and anti-CFH antibodies to SCRs19-20 has been reported to be the risk factor in aHUS. The authors speculate that the same link may be operative in LN impairing the CFH cell surface recognition [37]. The most recent study performed on a large cohort of 603 SLE Chinese patients (among them 334 with LN), and 350 controls found that the variants of the $C F H$ gene might affect the histopathologic subtypes and some clinical features of the disease. Namely, there was a significantly higher ratio of CC/CT genotypes of rs 1061170 (Y402H) in LN patients with class III than in the other two classes (class III vs. both class IV and V). Further, the GG genotype of rs6677604 was associated with the absence of anti-ds DNA antibody, while the AA genotype of rs 800292 (V62I) determined a higher level of circulating C3 in $\mathrm{LN}$ [65].

\section{Pauci-immune GN}

Pauci-immune GN comprises of both anti-neutrophil cytoplasmic antibodies (ANCA) positive and ANCA negative GN. Most cases (80-90\%) are ANCA positive and present morphologically as necrotizing crescentic glomerulonephritis (NCGN). On IF, only scanty Ig and complement (mainly C3c) deposits may be seen in glomeruli [7, 129]. According 
to the Chapel Hill Consensus, ANCA GN includes (SV), such as microscopic polyangiitis (MPA), granulomatosis with polyangiitis (GPA), or eosinophilic granulomatosis with polyangiitis (EGPA) [7, 130, 131]. Although ANCA positive SV is characterized by a paucity of Ig deposits (with C3 serum levels depleted only in approximately 35\% patients), recent studies strongly emphasize the role of the AP in the pathogenesis of the disease [130, 132, 133]. In this context, according to Finn et al., the average relative risk for the development of $\mathrm{SV}$ associated with the presence of a $\mathrm{C} 3 \mathrm{~F}$ allele was 2.6 (Table 1). This risk increased to 5.1 in C3FF homozygotes, indicating a gene dosage effect [55]. Similar results were obtained by Persson et al., where the incidence of the $\mathrm{C} 3 \mathrm{~F}$ allele was significantly higher in proteinase-3 (PR3)-ANCA positive patients compared to healthy controls. The authors assume the $\mathrm{C} 3 \mathrm{~F}$ allele may influence binding to the complement receptors and enhance the activation of neutrophils [56]. In another study, Manenti et al. reported that ANCA-SV patients with depleted C3 concentrations were older at the diagnosis, had lower glomerular filtration rate and features of TMA on biopsy. As low serum C3 levels usually reflect the activation of the AP, in 19 patients, $\mathrm{Bb}$ and MAC concentrations were assessed and shown to be significantly higher [133]. This data are consistent with a study performed by Gou et al., in which patients with active SV had elevated levels of activated AP complement proteins, such as $\mathrm{C} 3 \mathrm{a}, \mathrm{C} 5 \mathrm{a}, \mathrm{sC} 5 \mathrm{~b} 9$, and $\mathrm{Bb}$. The AP activation correlated with acute-phase reactants, number of crescents, and severity of kidney histology [134]. Moreover, Molad et al. [135] have shown that a low C3 plasma concentration at the time of diagnosis of myeloperoxidase (MPO)-ANCA positive SV was associated with reduced renal and patient survival. The most recent studies indicate $\mathrm{C} 5$ as a crucial factor in ANCA-SV pathogenesis. In an animal model, C5-deficient and CFB-deficient mice, injected with anti-MPO IgG, did not develop GN and SV. In comparison, the C4-depleted mice showed signs of SV [136]. Furthermore, mice lacking C5a receptor (c5aR or CD88) were protected against NCGN [137]. According to in vitro studies, C5a (among other proinflammatory factors) causes translocation of MPO and PR-3 to the cell surface in a process termed 'priming,' where they are targeted by ANCA. The interaction between ANCA and MPO or PR-3 results in neutrophils' degranulation, subsequent endothelial damage, and the AP activation. Due to the AP activation, more $\mathrm{C} 3 \mathrm{a}$ is generated and enhances inflammatory responses by recruiting more neutrophils $[132,138,139]$. However, the role of the AP in pauci-immune GN may be much more complicated. So far, in the one retrospective study, plasma levels of CFH in patients with active ANCA-SV have been lower in comparison with those in remission and inversely correlated with initial serum creatinine, the percentage of crescents on biopsy, and circulating levels of C3a, C5a, and
MAC [140]. Nevertheless, further studies are required to determine whether $\mathrm{CFH}$ abnormalities are involved in this pathology.

\section{Primary membranous nephropathy}

Primary membranous nephropathy (PMN) is a relatively rare disease (1.2/100,000/year), usually manifesting as the nephrotic syndrome. Although in $75 \%$ of cases it is considered to be the PMN, in the remaining $25 \%$ of cases, autoimmune diseases or malignancies have to be taken into account [131, 141]. According to the consensus report from 2015, PMN has not been included in the GN group [7]. Thickening of the glomerular capillary walls under LM along with peripheral deposits of IgG on IF is indicative for this disease. Classically, the subepithelial dense deposits on EM should support this diagnosis. The autoantibodies, mostly in the IgG4 subclass, targeting the phospholipase A2 receptors (PLA2R) on podocytes are considered to be the leading cause of subepithelial accumulation of the Ig deposits and subsequent activation of the complement resulting in the GBM injury [141, 142]. Since IgG4 is incapable of activating the $\mathrm{CP}$ and the deposits of MBL and $\mathrm{C} 4 \mathrm{~b}$ have been found in glomeruli of PMN patients, the LP is considered to play an essential role in the disease pathogenesis. However, the most recent studies show the prevalence of $\mathrm{Bb}$ deposits along with $\mathrm{C} 3 \mathrm{c}$ and $\mathrm{MAC}$, as well as increased urinary excretion of $\mathrm{C} 3 \mathrm{dg}$ and MAC suggesting the AP activation [131, 141, 143-145]. In fact, a patient with PMN and complete $\mathrm{C} 4$ deficiency has been reported, implicating that the disease may develop without the LP activation [146]. The prevalence of the C3Nef (Table 2) with low C3 levels has also been described in a case report of two unrelated children with PMN [147]. Also, another study reported the loss of glomerular heparan sulfate proteoglycans from the GBM, which bind CFH, causing local dysregulation of the AP [143]. Nevertheless, the role of the AP in PMN is still not well defined, and the exact pathophysiology remains to be determined.

\section{Conclusions}

Growing evidence of either acquired or hereditary abnormalities of the AP components suggests that this pathway may be a much more significant player in the pathogenesis of the glomerular diseases than previously expected. Dysfunctional $\mathrm{C} 3$ (as the main constituent of the $\mathrm{C} 3$ convertase) and $\mathrm{CFH}$ (as the principal AP inhibiting protein) may contribute to the glomerular pathology. As an example, C3G is a disease caused by the AP dysregulation in the fluid phase, arising due to acquired or genetic abnormalities of the AP components. The most affected $\mathrm{C} 3$ and $\mathrm{CFH}$ can be both 
the target of the autoantibodies and mutations, resulting in similar pathophysiological effect, which is prolonged C3 convertase activation and subsequent uncontrolled $\mathrm{C} 3$ consumption. Also, the AP seems to be essential in the development of diseases previously considered to be associated strictly with Ig deposition and the CP or LP activation, such as various types of immune-complex GNs. For instance, in the light of recent studies, SLE is characterized by the excessive complement system activation, and the $\mathrm{C} 3 \mathrm{~b}$ present in immune complexes in glomeruli activates the AP via amplification loop. Also, the abnormalities of the AP predispose to the renal manifestation of the disease. Insufficient AP inhibition may also increase the risk of $\operatorname{IgAN}$. However, it remains unexplained why $C F H R 3-1 \Delta$ polymorphism resulting in a more efficient AP C3 convertase decay, is protective against IgAN but confers the risk for SLE development. In pauci-immune GN, C5a protein contributes to the AP and neutrophils activation, leading to the vascular inflammation and damage. Some studies indicate the AP as a pathogenic factor of PMN since IgG4 is unable to activate CP and LP. Besides, the $\mathrm{C} 3 \mathrm{NeF}$, low $\mathrm{C} 3$ and $\mathrm{Bb}$ levels were found in PMN patients, suggesting the AP consumption. Nevertheless, the exact role of the AP in the pathogenesis of PMN is yet to be determined. The new insight of the role of CS and AP in particular in the pathogenesis of glomerular injury may lead to the introduction of the complement targeted therapies in the treatment of kidney disorders. Eculizumab, currently available complement inhibiting drug, successfully used in aHUS treatment, may prove to be an alternative in C3G and other glomerular diseases with the excessive AP consumption. However, in some patients, it may be insufficient. While acting directly on $\mathrm{C} 5$, it inhibits MAC formation and intravascular lysis, but the generation of $\mathrm{C} 3$ convertase and C3 amplification remains intact. Thus, a large amount of $\mathrm{C} 3 \mathrm{~b}$ is produced, with all pathophysiological consequences. In agreement with this, in the kidney diseases associated with dysregulation of the AP in a fluid phase, the blockade of $\mathrm{C} 3$ convertase seems to be the main goal. So far, several clinical trials using $\mathrm{C} 3$ convertase inhibitors, which might be potentially helpful in $\mathrm{C} 3 \mathrm{G}$, are being in progress. The blockade of $\mathrm{C} 3 \mathrm{bBb}$ may be achieved at different stages of C3 convertase assembly. For instance, agents targeting FD (lampalizumab and small molecule ACH-4471) and targeting FB (IONIS-FB-LRx) primarily designed for AMD may prove useful in $\mathrm{C} 3 \mathrm{G}$. The compstatin analogs, direct $\mathrm{C} 3$ inhibitors, by binding to the native $\mathrm{C} 3$ prevent its cleavage and the generation of all three complement pathways. Such potent interference in CS raises a question about the potential adverse effect, including the risk of life-threatening infections. The results of phase I of the clinical trial, involving Cp40-based drug candidate (AMY-101, Amyndas) on healthy male volunteers, assessing the safety profile of the drug are encouraging. Currently, phase Ib trial in patients with $\mathrm{C} 3 \mathrm{G}$ are in preparation. Another promising complement therapeutic target seems to be the prevention of $\mathrm{C} 5 \mathrm{a}$ signaling, which may be accomplished by the blockade of C5a complement receptor (C5aR1). Clinical trials regarding the use of an orally available small molecule C5aR1 antagonist (CCX168, Avacopan) in ANCA-SV, C3G, IgAN, and aHUS are in progress [148]. Nevertheless, experiments on animal models have shown that complement-targeting therapy has to be carried out with great caution, since our understanding of CS, although increasing, is still incomplete. Therefore, further studies on the mechanisms of the AP dysfunction and over-activation in glomerular diseases are required.

\section{Compliance with ethical standards}

Conflict of interests The authors declare no conflict of interest.

Open Access This article is distributed under the terms of the Creative Commons Attribution 4.0 International License (http://creativeco mmons.org/licenses/by/4.0/), which permits unrestricted use, distribution, and reproduction in any medium, provided you give appropriate credit to the original author(s) and the source, provide a link to the Creative Commons license, and indicate if changes were made.

\section{References}

1. Dunkelberger JR, Song WC. Complement and its role in innate and adaptive immune responses. Cell Res. 2010;20(1):34-50.

2. Rodriguez E, Nan R, Li K, Gor J, Perkins SJ. A revised mechanism for the activation of complement $\mathrm{C} 3$ to $\mathrm{C} 3 \mathrm{~b}$ : a molecular explanation of a disease-associated polymorphism. J Biol Chem. 2015;290(4):2334-50.

3. Sahu A, Lambris JD. Structure and biology of complement protein $\mathrm{C} 3$, a connecting link between innate and acquired immunity. Immunol Rev. 2001;180:35-48.

4. Singer L, Colten HR, Wetsel RA. Complement C3 deficiency: human, animal, and experimental models. Pathobiology. 1994;62(1):14-28.

5. Valero-Hervás DM, Morales $\mathrm{P}$, Castro MJ, et al. Complement C3 genotyping of slow and fast variants by real time PCR-high resolution melting. Eur J Infamm. 2012;10(3):329-34.

6. Delanghe JR, Speeckaert R, Speeckaert MM. Complement C3 and its polymorphism: biological and clinical consequences. Pathology. 2014;46(1):1-10.

7. Sethi S, Haas M, Markowitz GS, et al. Mayo clinic/renal pathology society consensus report on pathologic classification, diagnosis, and reporting of GN. J Am Soc Nephrol. 2016;27(5):1278-87.

8. Salvadori M, Bertoni E. Complement related kidney diseases: recurrence after transplantation. World J Transplant. 2016;6:632-45.

9. Fakhouri F, Frémeaux-Bacchi V, Noël LH, Cook HT, Pickering MC. C3 glomerulopathy: a new classification. Nat Rev Nephrol. 2010;6(8):494-9.

10. Pickering MC, D'Agati VD, Nester CM, et al. C3 glomerulopathy: consensus report. Kidney Int. 2013;84(6):1079-89. 
11. De Bruijn MHL, Fey GH. Human complement component C3: cDNA coding sequence and derived primary structure. Proc Natl Acad Sci. 1985;82:708-12.

12. Reis ES, Falcăo DA, Isaac L. Clinical aspects and molecular basis of primary deficiencies of complement component $\mathrm{C} 3$ and its regulatory proteins factor I and factor $\mathrm{H}$. Scand J Immunol. 2006;63(3):155-68.

13. Chen ZA, Pellarin R, Fischer L, et al. Structure of complement $\mathrm{C} 3\left(\mathrm{H}_{2} \mathrm{O}\right)$ revealed by quantitative cross-linking/mass spectrometry and modeling. Mol Cell Proteom. 2016;15(8):2730-43.

14. Janssen BJ, Christodoilidou A, McCarthy A, Lambris JD, Gross P. Structure of $\mathrm{C} 3 \mathrm{~b}$ reveals conformational changes that underlie complement activity. Nature. 2006;444(7116):213-6.

15. Thurman JM, Holers VM. The central role of the alternative complement pathway in human disease. J Immunol. 2006;176(3):1305-10.

16. Ricklin D, Reis ES, Lambris JD. Complement in disease: a defence system turning offensive. Nat Rev Nephrol. 2016;12(7):383-401.

17. Kemper C, Atkinson JP, Hourcade DE. Properdin: emerging roles of a pattern-recognition molecule. Annu Rev Immunol. 2010;28:131-55.

18. Pedersen DV, Roumenina L, Jensen RK, et al. Functional and structural insight into properdin control of complement alternative pathway amplification. EMBO J. 2017;36(8):1084-99.

19. Rooijakkers SH, Wu J, Ruyken M, et al. Structural and functional implications of the alternative complement pathway C3 convertase stabilized by a staphylococcal inhibitor. Nat Immunol. 2009;10(7):721-7.

20. Sarma JV, Ward PA. The complement system. Cell Tissue Res. 2011;343(1):227-35

21. Lachmann PJ. The amplification loop of the complement pathways. Adv Immunol. 2009;104:115-49.

22. Rochowiak A, Niemir ZI. The structure and role of CR 1 complement receptor in physiology. Pol Merkur Lekarski. 2010;28(163):79-83.

23. Merle NS, Church SEL, Fremeaux-Bacchi V, Roumenina LT. Complement system part I: molecular mechanisms of activation and regulation. Front Immunol. 2015;6:262.

24. Mathern DR, Heeger PS. Molecules great and small: the complement system. Clin J Am Soc Nephrol. 2015;10(9):1636-50.

25. Thurman JM, Nester CM. All things complement. Clin J Am Soc Nephrol. 2016;11(10):1856-66.

26. Merle NS, Noe R, Halbwachs-Mecarelli L, Fremeaux-Bacchi V, Roumenina LT. Complement system part II: role in immunity. Front Immunol. 2015;26(6):257.

27. Ritchie RF, Palomaki GE, Neveux LM, Navolotskaia O, Ledue TB, Craig WY. Reference distributions for complement proteins C3 and C4: a practical, simple and clinically relevant approach in a large cohort. J Clin Lab Anal. 2004;18(1):1-8.

28. Forneris F, Ricklin D, Wu J, et al. Structures of C3b in complex with factors $\mathrm{B}$ and $\mathrm{D}$ give insight into complement convertase formation. Science. 2010;330(6012):1816-20.

29. Forneris F, Wu J, Xue X, et al. Regulators of complement activity mediate inhibitory mechanisms through a common C3b-binding mode. EMBO J. 2016;35(10):1133-49.

30. Xue X, Wu J, Ricklin D, et al. Regulator-dependent mechanisms of $\mathrm{C} 3 \mathrm{~b}$ processing by factor I allow differentiation of immune responses. Nat Struct Mol Biol. 2017;24(8):643-51.

31. Appel GB, Cook HT, Hageman G, et al. Membranoproliferative glomerulonephritis type II (dense deposit disease): an update. J Am Soc Nephrol. 2005;16(5):1392-403.

32. Maillard N, Wyatt RJ, Julian BA, et al. Current understanding of the role of complement in IgA nephropathy. J Am Soc Nephrol. 2015;26:1503-12.
33. Wu J, Wu YQ, Ricklin D, Janssen BJ, Lambris JD, Gros P. Structure of complement fragment $\mathrm{C} 3 \mathrm{~b}$-factor $\mathrm{H}$ and implications for host protection by complement regulators. Nat Immunol. 2009;10(7):728-33.

34. Abrera-Abeleda MA, Nishimura C, Smith JL, et al. Variations in the complement regulatory genes factor $\mathrm{H}(\mathrm{CFH})$ and factor $\mathrm{H}$ related 5 (CFHR5) are associated with membranoproliferative glomerulonephritis type II (dense deposit disease). J Med Genet. 2006;43(7):582-9.

35. McRae JL, Duthy TG, Griggs KM, et al. Human factor H-related protein 5 has cofactor activity, inhibits C3 convertase activity, binds heparin and C-reactive protein, and associates with lipoprotein. J Immunol. 2005;174(10):6250-6.

36. Csincsi ÁI, Kopp A, Zöldi M, et al. Factor H-related protein 5 interacts with pentraxin 3 and the extracellular matrix and modulates complement activation. J Immunol. 2015;194(10):4963-73.

37. Medjeral-Thomas N, Pickering MC. The complement factor H-related proteins. Immunol Rev. 2016;274(1):191-201.

38. Goicoechea de Jorge E, Caesar JJ, Malik TH, et al. Dimerization of complement factor $\mathrm{H}$-related proteins modulates complement activation in vivo. Proc Natl Acad Sci USA. 2013;110(12):4685-90.

39. Tortajada A, Yébenes H, Abarrategui-Garrido C, et al. C3 glomerulopathy-associated CFHR 1 mutation alters FHR oligomerization and complement regulation. J Clin Invest. 2013;123(6):2434-46.

40. Chen Q, Wiesener M, Eberhardt HU, et al. Complement factor H-related hybrid protein deregulates complement in dense deposit disease. J Clin Invest. 2014;124(1):145-55.

41. Hebecker M, Józsi M. Factor H-related protein 4 activates complement by serving as a platform for the assembly of alternative pathway $\mathrm{C} 3$ convertase via its interaction with $\mathrm{C} 3 \mathrm{~b}$ protein. $\mathrm{J}$ Biol Chem. 2012;287(23):19528-36.

42. van Beek AE, Pouw RB, Brouwer MC, et al. Factor H-related (FHR)-1 and FHR-2 form homo- and heterodimers, while FHR-5 circulates only as homodimer in human plasma. Front Immunol. 2017;8:1328.

43. Wieme RJ, Demeulenaere L. Genetically determined electrophoretic variant of the human complement component C'3. Nature. 1967;214:1042-3.

44. Alper CA, Propp RP. Genetic polymorphism of the third component of human complement (C'3). J Clin Invest. 1968;47:2181-91.

45. Botto M, Fong KY, So AK, Koch C, Walport MJ. Molecular basis of polymorphisms of human complement component C3. J Exp Med. 1990;172:1011-7.

46. Torreira E, Tortajada A, Montes T, Rodríguez de Córdoba $\mathrm{S}$, Llorca O. 3D structure of the C3bB complex provides insights into the activation and regulation of the complement alternative pathway convertase. Proc Natl Acad Sci USA. 2009;106(3):882-7.

47. Yates JR, Sepp T, Matharu BK, et al. Complement C3 variant and the risk of age-related macular degeneration. N Engl J Med. 2007;357(6):553-61.

48. Bazyar N, Azarpira N, Khatami RS, Galehdari H. The investigation of allele and genotype frequencies of human C3 (rs2230199). Mol Biol Rep. 2012;39(9):8919-24.

49. Koch C, Behrendt N. A novel polymorphism of human complement component $\mathrm{C} 3$ detected by means of a monoclonal antibody. Immunogenetics. 1986;23:322-5.

50. Abrera-Abeleda MA, Nishimura C, Frees K, et al. Allelic variants of complement genes associated with dense deposit disease. $\mathrm{J}$ Am Soc Nephrol. 2011;22(8):1551-9.

51. Finn JE, Mathieson PW. Molecular analysis of C3 allotypes in patients with nephritic factor. Clin Exp Immunol. 1993;91:410-4. 
52. McLean RH, Winkelstein JA. Genetically determined variation in the complement system: relationship to disease. J Pediatr. 1984;105:179-88.

53. Finn JE, Li PK, Lai KN, Mathieson PW. Molecular analysis of C3 allotypes in Chinese patients with immunoglobulin A nephropathy. Am J Kidney Dis. 1994;23:543-6.

54. Rambausek M, van den Wall Bake AW, Schumacher-Ach R, et al. Genetic polymorphism of C3 and Bf in IgA nephropathy. Nephrol Dial Transplant. 1987;2:208-11.

55. Finn JE, Zhang L, Agrawal S, Jayne DR, Oliveira DB, Mathieson PW. Molecular analysis of C3 allotypes in patients with systemic vasculitis. Nephrol Dial Transplant. 1994;9:1564-7.

56. Persson U, Gullstrand B, Pettersson AG, Truedsson L, Segelmark MA. A candidate gene approach to ANCA-associated vasculitis reveals links to the C3 and CTLA-4 genes but not to the IL1-Ra and Fcă-RIIa genes. Kidney Blood Press Res. 2013;37:641-8.

57. Brown KM, Kondeatis E, Vaughan RW, et al. Influence of donor C3 allotype on late renal-transplantation outcome. N Engl J Med. 2006;354:2014-23.

58. Matsuyama W, Nakagawa M, Takashima H, Muranaga F, Sano Y, Osame M. Identification of a novel mutation(Tyr1081Ter) in sisters with hereditary component C3 deficiency and SLE-like symptoms. Hum Mutat. 2001;17(1):79.

59. Miyagawa H, Yamai M, Sakaguchi D, et al. Association of polymorphisms in complement component $\mathrm{C} 3$ gene with susceptibility to systemic lupus erythematosus. Rheumatology (Oxford). 2008;47(2):158-64.

60. Rhodes B, Hunnangkul S, Morris DL, Hsaio LC, Graham DS, Nitsch D. The heritability and genetics of complement C3 expression in UK SLE families. Genes Immun. 2009;10(5):525-30.

61. Chauvet S, Roumenina LT, Bruneau S, et al. A familial C3GN secondary to defective $\mathrm{C} 3$ regulation by complement receptor 1 and complement factor H. J Am Soc Nephrol. 2016;27(6): 1665-77.

62. Servais A, Noël LH, Roumenina LT, et al. Acquired and genetic complement abnormalities play critical role in dense deposit disease and other C3 glomerulopathies. Kidney Int. 2012;82(4):454-64.

63. Tortajada A, Montes T, Martínez-Barricarte R, Morgan BP, Harris CL, de Córdoba SR. The disease protective complement factor $\mathrm{H}$ allotypic variant Ile62 shows increased binding for $\mathrm{C} 3 \mathrm{~b}$ and enhanced cofactor activity. Hum Mol Genet. 2009;18:3452-61.

64. Iatropoulos $\mathrm{P}$, Noris $\mathrm{M}$, Melea $\mathrm{C}$, et al. Complement gene variants determine the risk of immunoglobulin-associated MPGN and C3 glomerulopathy and predict long-term renal outcome. Mol Immunol. 2016;71:131-42.

65. Tan M, Hao JB, Chu H, et al. Genetic variants in FH are associated with renal histopathologic subtypes of lupus nephritis: a large cohort study from China. Lupus. 2017;1:961203317702254.

66. Skerka C, Lauer N, Weinberger AA, et al. Defective complement control of factor $\mathrm{H}(\mathrm{Y} 402 \mathrm{H})$ and FHL-1 in age-related macular degeneration. Mol Immunol. 2007;44(13):3398-406.

67. Servais A, Noël LH, Frémeaux-Bacchi V, Lesavre P. C3 glomerulopathy. Contrib Nephrol. 2013;181:185-93.

68. Sethi S, Fervenza FC, Zhang Y, Nasr SH, Leung N, Vrana J. Proliferative glomerulonephritis secondary to dysfunction of the alternative pathway of complement. Clin J Am Soc Nephrol. 2011;6(5):1009-17.

69. Zhao J, Wu H, Khosravi M, et al. Association of genetic variants in complement factor $\mathrm{H}$ and factor $\mathrm{H}$-related genes with systemic lupus erythematosus susceptibility. PLoS Genet. 2011;7(5):e1002079.

70. Zhu L, Zhai YL, Wang FM, et al. Variants in complement factor $\mathrm{H}$ and complement factor $\mathrm{H}$-related protein genes, CFHR3 and CFHR1, affect complement activation in IgA nephropathy. J Am Soc Nephrol. 2015;26(5):1195-204.
71. Gharavi AG, Kiryluk K, Choi M, et al. Genome-wide association study identifies susceptibility loci for IgA nephropathy. Nat Genet. 2011;43:321-7.

72. Kiryluk K, Li Y, Scolari F, et al. Discovery of new risk loci for IgA nephropathy implicates genes involved in immunity against intestinal pathogens. Nat Genet. 2014;46(11):1187-96.

73. Nozal P, Garrido S, Martínez-Ara J, et al. Case report: lupus nephritis with autoantibodies to complement alternative pathway proteins and C3 gene mutation. BMC Nephrol. 2015;16:40.

74. Tsukamoto H, Horiuchi $\mathrm{T}$, Kokuba $\mathrm{H}$, et al. Molecular analysis of a novel hereditary $\mathrm{C} 3$ deficiency with systemic lupus erythematosus. Biochem Biophys Res Commun. 2005;330(1):298-304.

75. Gale DP, de Jorge EG, Cook HT, et al. Identification of a mutation in complement factor H-related protein 5 in patients of Cypriot origin with glomerulonephritis. Lancet. 2010;376(9743):794-801.

76. Malik TH, Lavin PJ, Goicoechea de Jorge E, et al. A hybrid CFHR3-1 gene causes familial C3 glomerulopathy. J Am Soc Nephrol. 2012;23(7):1155-60.

77. Xiao X, Ghosseinc C, Tortajada A, et al. Familial C3 glomerulonephritis caused by a novel CFHR5-CFHR2 fusion gene. Mol Immunol. 2016;77:89-96.

78. Togarsimalemath SK, Sethi SK, Duggal R, et al. A novel CFHR1CFHR5 hybrid leads to a familial dominant C3 glomerulopathy. Kidney Int. 2017;92(4):876-87.

79. Alfakeeh K, Azar M, Alfadhel M, Abdullah AM, Aloudah N, Alsaad KO. Rare genetic variant in the CFB gene presenting as atypical hemolytic uremic syndrome and immune complex diffuse membranoproliferative glomerulonephritis, with crescents, successfully treated with eculizumab. Pediatr Nephrol. 2017;32(5):885-91.

80. Marinozzi MC, Vergoz L, Rybkine T, et al. Complement factor $\mathrm{B}$ mutations in atypical hemolytic uremic syndrome-diseaserelevant or benign? J Am Soc Nephrol. 2014;25(9):2053-65.

81. Medjeral-Thomas NR, O'Shaughnessy MM, O'Regan JA, et al. C3 glomerulopathy: clinicopathologic features and predictors of outcome. Clin J Am Soc Nephrol. 2014;9(1):46-53.

82. Cook HT. C3 glomerulopathy. F1000Research. 2017;6:248.

83. Elfituri O, Aardsma N, Setty S, Behm F, Czech K. Atypical plasmacytic proliferation in a case of $\mathrm{C} 3$ glomerulopathy: pathophysiology demystified. J Investig Med High Impact Case Rep. 2017;5(1):2324709617690746. https://doi.org/10.1177/23247 09617690746

84. Ito N, Ohashi R, Nagata M. C3 glomerulopathy and current dilemmas. Clin Exp Nephrol. 2017;21(4):541-51.

85. Misra A, Peethambaram A, Garg A. Clinical features and metabolic and autoimmune derangements in acquired partial lipodystrophy: report of 35 cases and review of the literature. Medicine (Baltimore). 2004;83(1):18-34.

86. Rose KL, Paixao-Cavalcante D, Fish J, et al. Factor I is required for the development of membranoproliferative glomerulonephritis in factor H-deficient mice. J Clin Invest. 2008;118(2):608-18.

87. Jansen JH. Porcine membranoproliferative glomerulonephritis with intramembranous dense deposits (porcine dense deposit disease). APMIS. 1993;101(4):281-9.

88. Høgåsen K, Jansen JH, Mollnes TE, Hovdenes J, Harboe M. Hereditary porcine membranoproliferative glomerulonephritis type II is caused by factor $\mathrm{H}$ deficiency. J Clin Invest. 1995;95(3):1054-61.

89. Pickering MC, Cook HT, Warren J, et al. Uncontrolled C3 activation causes membranoproliferative glomerulonephritis in mice deficient in complement factor H. Nat Genet. 2002;31(4):424-8.

90. Pickering MC, Warren J, Rose KL, et al. Prevention of C5 activation ameliorates spontaneous and experimental glomerulonephritis in factor H-deficient mice. PNAS. 2006;103(25):9649-54. 
91. Ruseva MM, Vernon KA, Lesher AM, et al. Loss of properdin exacerbates $\mathrm{C} 3$ glomerulopathy resulting from factor $\mathrm{H}$ deficiency. J Am Soc Nephrol. 2013;24(1):43-52.

92. Lesher AM, Zhou L, Kimura Y, et al. Combination of factor $\mathrm{H}$ mutation and properdin deficiency causes severe C3 glomerulonephritis. J Am Soc Nephrol. 2013;24(1):53-65.

93. Zand L, Kattah A, Fervenza FC, et al. C3 Glomerulonephritis associated with monoclonal gammopathy. Am J Kidney Dis. 2013;62(3):506-14.

94. Sethi S, Sukov WR, Zhang Y, et al. Dense deposit disease associated with monoclonal gammopathy of undetermined significance. Am J Kidney Dis. 2010;56(5):977-82.

95. Marinozzi MCh, Roumenina LT, Chauvet S, et al. Anti-factor $\mathrm{B}$ and anti-C3b autoantibodies in $\mathrm{C} 3$ glomerulopathy and Igassociated membranoproliferative GN. J Am Soc Nephrol. 2017;28(5):1603-13.

96. Paixão-Cavalcante D, López-Trascasa M, Skattum L, et al. Sensitive and specific assays for C3 nephritic factors clarify mechanisms underlying complement dysregulation. Kidney Int. 2012;82(10):1084-92.

97. Daha MR, Fearon DT, Austen KF. C3 nephritic factor (C3NeF): stabilization of fluid phase and cell-bound alternative pathway convertase. J Immunol. 1976;116(1):1-7.

98. Marinozzi MC, Chauvet S, Le Quintrec M, et al. C5 nephritic factors drive the biological phenotype of $\mathrm{C} 3$ glomerulopathies. Kidney Int. 2017;92(5):1232-41.

99. Blanc C, Togarsimalemath SK, Chauvet S, et al. Anti-factor H autoantibodies in $\mathrm{C} 3$ glomerulopathies and in atypical hemolytic uremic syndrome: one target, two diseases. J Immunol. 2015;194(11):5129-38.

100. Martínez-Barricarte R, Heurich M, Valdes-Cañedo F, VazquezMartul E, Torreira E, Montes T. Human C3 mutation reveals a mechanism of dense deposit disease pathogenesis and provides insights into complement activation and regulation. $\mathbf{J}$ Clin Invest. 2010;120(10):3702-12.

101. Chen P, Zhu L, Yu F, et al. Different types of glomerulonephritis associated with the dysregulation of the complement alternative pathway in 2 brothers: a case report. Medicine (Baltimore). 2017;96(24):e7144.

102. Habbig S, Mihatsch MJ, Heinen S, et al. C3 deposition glomerulopathy due to a functional factor $\mathrm{H}$ defect. Kidney Int. 2009;75(11):1230-4.

103. Noris M, Remuzzi G. Glomerular diseases dependent on complement activation, including atypical hemolytic uremic syndrome, membranoproliferative glomerulonephritis, and C3 glomerulopathy: core curriculum 2015. Am J Kidney Dis. 2015;66(2):359-75.

104. Schramm EC, Roumenina LT, Rybkine T, et al. Mapping interactions between complement $\mathrm{C} 3$ and regulators using mutations in atypical hemolytic uremic syndrome. Blood. 2015;125(15):2359-69.

105. Jokiranta TS. HUS and atypical HUS. Blood. 2017;129(21):2847-56.

106. Goodship TH, Cook HT, Fakhouri F, et al. Atypical hemolytic uremic syndrome and $\mathrm{C} 3$ glomerulopathy: conclusions from a "kidney disease: improving global outcomes" (KDIGO) controversies conference. Kidney Int. 2017;91(3):539-51.

107. Roumenina LT, Rayes J, Frimat M, Fremeaux-Bacchi V. Endothelial cells: source, barrier, and target of defensive mediators. Immunol Rev. 2016;274(1):307-29.

108. Dragon-Durey MA, Sethi SK, Bagga A, et al. Clinical features of anti-factor $\mathrm{H}$ autoantibody-associated hemolytic uremic syndrome. J Am Soc Nephrol. 2010;21(12):2180-7.

109. Józsi M, Licht C, Strobel S, et al. Factor H autoantibodies in atypical hemolytic uremic syndrome correlate with CFHR1/ CFHR3 deficiency. Blood. 2008;111(3):1512-4.
110. Murphy B, Georgiou T, Machet D, Hill P, McRae J. Factor H-related protein-5: a novel component of human glomerular immune deposits. Am J Kidney Dis. 2002;39(1):24-7.

111. Salvadori M, Rosso G. Reclassification of membranoproliferative glomerulonephritis: identification of a new GN: C3GN. World J Nephrol. 2016;5(4):308-20.

112. Smykał-Jankowiak K, Niemir ZI, Polcyn-Adamczak M. Do circulating antibodies against $\mathrm{C} 1 \mathrm{q}$ reflect the activity of lupus nephritis? Pol Arch Med Wewn. 2011;121(9):287-95.

113. Tongmao Z. Genetic polymorphisms of $\mathrm{C} 3$ and $\mathrm{Bf}$ in the Chinese population. Hum Hered. 1983;33(1):36-8.

114. Yang X, Wei RB, Wang Y, et al. Decreased serum C3 levels in immunoglobulin A ( $\operatorname{IgA}$ ) nephropathy with chronic kidney disease: a propensity score matching study. Med Sci Monit. 2017;23:673-81.

115. Jullien P, Laurent B, Claisse G, et al. Deletion variants of CFHR1 and CFHR3 associate with mesangial immune deposits but not with progression of IgA nephropathy. J Am Soc Nephrol. 2018;29(2):661-9.

116. Medjeral-Thomas NR, Lomax-Browne HJ, Beckwith H, et al. Circulating complement factor $\mathrm{H}$-related proteins 1 and 5 correlate with disease activity in IgA nephropathy. Kidney Int. 2017;92(4):942-52.

117. Tortajada A, Gutiérrez E, Goicoechea de Jorge E, et al. Elevated factor $\mathrm{H}$-related protein 1 and factor $\mathrm{H}$ pathogenic variants decrease complement regulation in IgA nephropathy. Kidney Int. 2017;92(4):953-63.

118. Niemir ZI, Wągrowska-Danilewicz M. Renal involvement in systemic lupus erythematosus. Pol Merkur Lekarski. 2010;28(164):144-51.

119. Almaani S, Meara A, Rovin BH. Update on lupus nephritis. Clin J Am Soc Nephrol. 2017;12(5):825-35.

120. Wakiguchi H, Takei S, Kubota T, Miyazono A, Kawano Y. Treatable renal disease in children with silent lupus nephritis detected by baseline biopsy: association with serum C3 levels. Clin Rheumatol. 2017;36(2):433-7.

121. Smykał-Jankowiak K, Niemir ZI. Structure and function of complement protein $\mathrm{C} 1 \mathrm{q}$ and its role in the development of autoimmune diseases. Postepy Hig Med Dosw (Online). 2009;63:134-41.

122. Orbai AM, Truedsson L, Sturfelt G, et al. Anti-C1q antibodies in systemic lupus erythematosus. Lupus. 2015;24(1):42-9.

123. Manenti L, Urban ML, Vaglio A, David S. Persistent reduction of serum $\mathrm{C} 3$ and lupus nephritis outcome: a retrospective observational study. Nephrol Dial Transpl. 2015;30(Suppl 3):422-3.

124. Wang SY, Zhang Y, Xu Y, Chen JH. Persistence of low serum C3 level is associated with higher relapse rate and influences prognosis in lupus nephritis. Hong Kong J Nephrol. 2015;17(2):S56.

125. Song D, Guo W, Wang F, et al. Complement alternative pathway's activation in patients with lupus nephritis. Am J Med Sci. 2017;353(3):247-57.

126. Vasilev VV, Noe R, Dragon-Durey MA, et al. Functional characterization of autoantibodies against complement component C3 in patients with lupus nephritis. J Biol Chem. 2015;290(42):25343-55.

127. Birmingham DJ, Bitter JE, Ndukwe EG, et al. Relationship of circulating anti-C3b and anti-C1q IgG to lupus nephritis and its flare. Clin J Am Soc Nephrol. 2016;11(1):47-53.

128. Bao L, Haas M, Quigg RJ. Complement factor H deficiency accelerates development of lupus nephritis. J Am Soc Nephrol. 2011;22(2):285-95.

129. Chen M, Xing GQ, Liu FYG, Zhao MH. Complement deposition in renal histopathology of patients with ANCA-associated 
pauci-immune glomerulonephritis. Nephrol Dial Transplant. 2009;24(4):1247-52.

130. Jennette JCh, Xiao H, Hu P. Complement in ANCA-associated vasculitis. Semin Nephrol. 2013;33(6):557-64.

131. Kościelska-Kasprzak K, Bartoszek D, Myszka M, Żabińska M, Klinger M. The complement cascade and renal disease. Arch Immunol Ther Exp (Warsz). 2014;62(1):47-57.

132. Chen M, Daha MR, Kallenberg CG. The complement system in systemic autoimmune disease. J Autoimmun. 2010;34(3):J276-86.

133. Manenti L, Vaglio A, Gnappi E, et al. Association of serum C3 concentration and histologic signs of thrombotic microangiopathy with outcomes among patients with ANCA-associated renal vasculitis. Clin J Am Soc Nephrol. 2015;10:2143-51.

134. Gou SJ, Juan J, Chen M, Yu F, Zhao MH. Circulating complement activation in patients with anti-neutrophil cytoplasmic antibody-associated vasculitis. Kidney Int. 2013;83:129-37.

135. Molad Y, Tovar A, Ofer-Shiber S. Association of low serum complement $\mathrm{C} 3$ with reduced patient and renal survival in antimyeloperoxidase-associated small-vessel vasculitis. Nephron Clin Pract. 2014;126:67-74.

136. Xiao H, Schreiber A, Heeringa P, Falk RJ, Jennette JC. Alternative complement pathway in the pathogenesis of disease mediated by anti-neuthrophil cytoplasmic autoantibodies. Am J Pathol. 2007;170(1):52-64.

137. Xiao H, Dairaghi DJ. Powers JP el al. C5a receptor (CD88) blockade protects against MPO-ANCA GN. J Am Soc Nephrol. 2014;25(2):225-31.

138. Chen M, Jayne DRW, Zhao MH. Complement in ANCA associated vasculitis: mechanisms and implications for menagment. Nat Rev Nephrol. 2017;13(6):359-67.
139. Kettritz R. How anti-neutrophil cytoplasmic autoantibodies activate neutrophils. Clin Exp Immunol. 2012;169(3):220-8.

140. Chen SF, Wang FM, Li ZY, Yu F, Zhao MH, Chen M. Plasma complement factor $\mathrm{H}$ is associated with disease activity of patients with ANCA-associated vasculitis. Arthritis Res Ther. 2015;17:129.

141. Ma H, Sandor DG, Beck LH. The role of complement in membranous nephropathy. Semin Nephrol. 2013;33(6):531-42.

142. Doi T, Mayumi M, Kanatsu K, Suehiro F, Hamashima Y. Distribution of IgG subclasses in membranous nephropathy. Clin Exp Immunol. 1984;58(1):57-62.

143. Borza DB. Alternative pathway dysregulation and the conundrum of complement activation by IgG4 immune complexes in membranous nephropathy. Front Immunol. 2016;7:157.

144. Segawa Y, Hisano S, Matsushita M, et al. IgG subclasses and complement pathway in segmental and global membranous nephropathy. Pediatr Nephrol. 2010;25(6):1091-9.

145. Brenchley PE, Coupes B, Short CD, O'Donoghue DJ, Ballardie FW, Mallick NP. Urinary C3dg and C5b-9 indicate active immune disease in human membranous nephropathy. Kidney Int. 1992;41:933-7.

146. Lhotta K, Würzner R, Rumpelt HJ, Eder P, Mayer G. Membranous nephropathy in a patient with hereditary complete complement C4 deficiency. Nephrol Dial Transplant. 2004;19(4):990-3. https://doi.org/10.1093/ndt/gfh008.

147. Niel O, Dallocchio A, Thouret MC, et al. C3 nephritic factor can be associated with membranous glomerulonephritis. Pediatr Nephrol. 2015;30(2):353-5.

148. Ricklin D, Mastellos DC, Reis ES, Lambris JD. The renaissance of complement therapeutics. Nat Rev Nephrol. 2018;14(1):26-47. 